\section{Activismo juvenil en partidos con gestiones de gobierno a nivel subnacional en Argentina (2007-2015)}

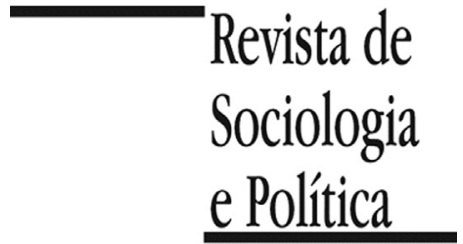

DOI 10.1590/1678-987317256405

\author{
Melina Vázquez y Alejandro Cozachcow
}

\title{
Resumen
}

El trabajo propone explorar las condiciones de posibilidad y los modos en que se produce un ciclo de participación política juvenil en Argentina que encuentra en los espacios político-partidarios uno de sus renovados escenarios. Luego de una profunda crisis de representación política que llevó al activismo juvenil a impugnar la política en relación con sus manifestaciones político-partidarias y estatales, los partidos políticos comenzaron a recrear espacios de militancia juvenil, al mismo tiempo que fueron receptores de nuevos activistas que entran a la política. En este proceso se destaca el peso que cobraron partidos políticos que, además, estuvieron a cargo de gestiones de gobierno a nivel nacional y subnacional. En el artículo se busca analizar qué rasgos, propiedades y características dan forma a una nueva figura de activismo entre los y las jóvenes que forman parte de estas experiencias. Más concretamente, propone analizar cómo se ingresa a la militancia, qué sentidos se construyen sobre la misma y qué relaciones se producen entre el activismo y el trabajo en el Estado en relación con dos partidos que se ocupan de gestiones de gobierno en la Provincia de Santa Fe (de la mano del Partido Socialista) y en la Ciudad Autónoma de Buenos Aires (por parte de Propuesta Republicana). Se recupera la sociología francesa del activismo militante para mostrar quiénes son los y las jóvenes activistas que militan en ambos partidos, de qué modos participan dentro de los mismos, así como en las gestiones de gobierno de sus respectivos partidos, y qué significados se construyen en torno a las articulaciones y desplazamientos entre las carreras militantes y laborales de las y los activistas. El enfoque que sigue el trabajo permite pensar elementos comunes en relación con los activismos juveniles en partidos en/de gestión más allá de las diferencias político-ideológicas que los caracterizan. El artículo recoge resultados de una investigación más amplia realizada en el Equipo de Estudios de Políticas y Juventudes (IIGG-UBA) sobre la participación juvenil en partidos políticos en Argentina. En este caso en particular, se recuperan las entrevistas en profundidad realizadas a dirigentes y militantes juveniles con distintos niveles de responsabilidad dentro de cada partido; encuestas fueran aplicadas con jóvenes de ambos partidos y observaciones participantes realizadas en instancias de reunión definidas como juveniles por parte de ambos partidos.

Palabras-clave: juventudes; política argentina; militancia; partidos políticos; participación política.

Recibido en el 8 de Agosto de 2016. Aprobado en el 16 de Enero de 2017.

\section{Introducción ${ }^{1}$}

\footnotetext{
${ }^{1}$ Agradecemos las sugerencias y comentarios de los dictaminadores anónimos de la Revista de Sociología e Política.
}

$\mathrm{E}$ n los últimos años se registra una revitalización de las formas de participación juvenil en América Latina que reconoce interesantes mutaciones y transformaciones en relación con otros ciclos emblemáticos de movilización juvenil del pasado reciente. La aparición de nuevos grupos y colectivos definidos como juveniles, articulados con modos específicos de escenificación y de puesta en escena, la emergencia de nuevos reclamos y demandas que muestran una reconfiguración de la escena pública se hace evidente tanto por el reencantamiento con lo público (Aguilera 2011) como también por el proceso de creciente politización juvenil (Cipagauta et al., 2015; Vommaro 2015).

En el caso argentino, la movilización y participación juvenil se constituye, sin lugar a dudas, en un tema central de la agenda política, sobre todo desde el primer gobierno de Cristina Fernández de Kirchner (2007-2011); período en el que se observa una consagración y legitimación pública de las juventudes 
2 Para profundizar acerca de las características de este nuevo ciclo de movilizaciones en América Latina, consultar Valenzuela Arce (2015), Vommaro (2015), Aguilera (2011), entre otros.

\footnotetext{
${ }^{3}$ Conflicto que se manifestó en masivas movilizaciones a favor y en contra de la implementación de retenciones a la exportación agropecuaria, medida descartada en una votación del Senado de la Nación desempatada por el entonces Vicepresidente Julio Cobos, quien voto en contra de la medida impulsada por su propio gobierno.

${ }^{4}$ Para profundizar, véase Enrique (2010), Beltrán y Falconi (2011) y Núñez (2013).

5 Joven militante del Partido Obrero asesinado en 2010 en
}

movilizadas (Vázquez 2015). El caso resulta interesante, además, en la medida en que muestra importantes diferencias tanto con la movilización juvenil en Argentina en períodos anteriores, así como también en comparación con los grupos, modos de organización y tipos de acciones colectivas juveniles que emergieron en otros países en los cuales las juventudes también han recobrado centralidad en la escena política.

Con respecto a lo primero, durante la larga década neoliberal (Bonvilani et al., 2010), esto es, entre mediados de la década del 90 y principios de la década siguiente, se observa la proliferación de proyectos de militancia asociados centralmente al impulso de un activismo barrial o de base, que impugna la relación con el Estado así como los modelos de militancia asociados con los partidos políticos, los sindicatos y otras instancias de representación política que son acusadas de ser delegativas, verticalistas y centralistas. Estas experiencias proliferan fuertemente y facilitan la construcción de activismos juveniles que, en ocasiones, pasaron inadvertidos debido a la escasa visibilidad pública de algunos de estos proyectos y modos de tramitar los compromisos militantes.

Con respecto a lo segundo, la reemergencia de las juventudes en la agenda política en el contexto local coincide temporalmente con el ciclo de movilizaciones juveniles en otros países de América Latina ${ }^{2}$, sin embargo en el caso argentino reconoce condiciones particulares: se trata de experiencias fuertemente articuladas, de diferentes modos, con la revitalización de la vida institucional y político partidaria. En este sentido, se observa la presencia de más y nuevos activistas juveniles en los partidos como también la (re) emergencia de espacios de juventud diferenciados dentro de los mismos. Por otra parte, se registra un reconocimiento militante de las juventudes desde las capas dirigenciales (adultas), que puede ser observada, a modo de ejemplo, en la promoción de candidaturas jóvenes en lugares expectantes de las listas electorales.

De acuerdo con lo dicho, en el presente artículo proponemos explorar las condiciones de posibilidad y los modos en que se observa la revitalización del activismo juvenil en torno a espacios partidarios, así como también las principales características que presenta la construcción de los compromisos militantes juveniles. No solamente nos interesa comprender cómo militan las juventudes en partidos políticos sino además -y fundamentalmente -dar cuenta de los impactos que posee el desarrollo de compromisos militantes en partidos que, a su vez, forman parte de gestiones de gobierno. Partimos de la hipótesis de que a fines de la primera década del siglo XXI se configura en Argentina un contexto de oportunidad para entrar a la política (Offerlé 1998) por parte de un conjunto de activistas en espacios juveniles. La literatura ha mostrado la importancia que cobran en este contexto un conjunto de hitos que son enmarcados colectivamente en un sentido que propicia la movilización de adhesiones militantes juveniles. Concretamente: la llamada crisis del campo en el año $2008^{3}$, las tomas de escuelas secundarias en centros urbanos ${ }^{4}$, el asesinato del militante Mariano Ferreyra $^{5}$ y la muerte de Néstor Kirchner en $2010^{6}$. Estos hitos marcan no solamente el ingreso a la militancia, sino además la construcción de un ciclo de movilización política juvenil. Aunque el la revitalización del activismo juvenil se reconoce en una multiplicidad de espacios, partidos y organizaciones pertenecientes a un heterogéneo espectro político-ideológico (que interpelan al mismo tiempo que son receptores de esta militancia), en aquellos partidos que pasan a ser parte de gestiones de gobierno en diferentes niveles (nacional y provincial, centralmente) cobra características particulares. Así, el hecho de ser gestión impulsa, además de nuevos activismos juveniles, nuevas maneras de entender y tramitar los compromisos políticos entre los recién llegados.

En este trabajo analizamos las experiencias de jóvenes militantes vinculados con dos espacios político-partidarios que presentan marcadas diferencias en 
una manifestación de trabajadores ferroviarios tercerizados por un grupo de afiliados del principal sindicato del sector.

${ }^{6}$ Fallecido el 27 de Septiembre de 2010. En la multitudinaria despedida pública se observó una importante cantidad de jóvenes, al mismo tiempo su figura pasó a incorporarse a la estética de un conjunto de grupos juveniles movilizados. cuanto a su historia, a su perfil político ideológico y su organización interna pero que comparten dos aspectos comunes: 1) son partidos en los que se produce un revitalización así como un creciente impulso de la participación juvenil, que se manifiesta tanto en el crecimiento del activismo joven, como también la centralidad que cobra la cuestión juvenil en la construcción político-partidaria; 2) son partidos que forman parte de gobiernos a nivel provincial desde el año 2007. Nos referimos al Partido Socialista en la Provincia de Santa Fe y a Propuesta Republicana (PRO) - ver lista de siglas en el Apéndice I al final del artículo - en la Ciudad Autónoma de Buenos Aires (CABA), los cuales, como señala Mauro (2016), son casos representativos de un fenómeno novedoso en la política Argentina de consolidación de terceras fuerzas políticas con proyección nacional que accedieron y retuvieron el control de un gobierno provincial.

Ahora bien, el trabajo no busca estudiar los partidos políticos sino más bien las formas de participar en los mismos y, más específicamente, la relación entre la participación política y las juventudes al interior de diferentes espacios partidarios y las gestiones de gobierno de las que forman parte. Se busca, en este sentido, caracterizar al universo de militantes juveniles así como también mostrar las maneras que en que construyen sentidos y prácticas militantes a partir de la vinculación con espacios partidarios vinculados con gestiones de gobierno. En otros términos, nos interesa desentrañar los sentidos entre militancia, política y gestión pública. ${ }^{7}$

Según Franz (2016), los abordajes de las formas de participación en los partidos políticos se pueden agrupar en dos grandes tradiciones. Una que se vincula el paradigma dominante en la ciencia política anglosajona, cuyas bases remiten al estructural-funcionalismo y realizan investigaciones predominantemente cuantitativas; la otra recupera los aportes de la sociología política francesa, cuyos fundamentos teóricos se extraen del interaccionismo simbólico y se caracteriza por el impulso de estudios de corte cualitativo. Este artículo se sitúa en la segunda línea de trabajos mencionados y busca, en este sentido, analiza la militancia juvenil partidaria recuperando los aportes de la sociología francesa del compromiso militante (Pudal 2011; Agrikoliansky 2001; Fillieule 2015), así como también del enfoque sociohistórico de Michel Offerlé (1998; 2011). Esta perspectiva se vuelve productiva para analizar y comprender, por un lado, cómo se configuran espacios diferenciados para la participación juvenil al interior de cada partido, cómo, cuándo y por qué se incorpora una agenda juvenil y en qué sentido se reconoce una mayor capacidad de reclutamiento militante juvenil. En este sentido, permite explorar las relaciones entre el partido y el entorno partidario (Sawicki 2011), incorporando al análisis la consideración de las redes de sociabilidad, los modos en que se produce el reclutamiento, las maneras y momentos de ingreso al activismo partidario así como los modos y los espacios en los que se produce la socialización militante. Al mismo tiempo, esta mirada tiende a proponer lecturas no normativas acerca del compromiso político, pudiendo establecer relaciones entre la exploración de las carreras militantes y las carreras laborales y profesionales de los activistas. De acuerdo con esto, el enfoque escogido facilita el desarrollo de una lectura descriptiva al mismo tiempo que comprensiva del activismo juvenil en partidos que son gestión. En síntesis, la perspectiva que sigue el trabajo permite entender que no analizamos partidos políticos, sino más bien participación juvenil vinculada con los mismos ${ }^{8}$. Esto hace posible caracterizar y comprender elementos comunes entre militancias en partidos que presentan marcadas diferencias entre sí.

Por otra parte, el trabajo se inserta en el campo de los estudios de la participación juvenil, que fue objeto de análisis en contexto Europeo (Lafont 2001; Barberá, Barrio \& Rodríguez 2002; Hooghe \& Stolle 2005; Dechezelles 2008; Bargel \& Petifilis 2009), Norteamericano (Young \& Cross 2008; Binmilitancia partidaria sin indagar en la cantidad de afiliaciones jóvenes más allá de que afiliarse pueda ser un rito de pasaje entre jóvenes del PS (Cozachcow 2015). En la argentina el número de amplia de participación y

7 La aproximación desde el
nivel provincial de la que parte
este trabajo constituye
centralmente una estrategia
metodológica. Por ello, no
intenta profundizar en el
debate en torno a la política
subnacional en Argentina, tal
como lo hacen estudios como
los de Mauro, Ortiz de Rozas
y Paratz (2016), sino más bien
retomar la escala para
comparar militancias juveniles
en partidos que gobiernan. 
afiliados a partidos en tanto dato que representa una "ficción" (Mustapic 2002), resulta problemático para analizar los perfiles de la militancia juvenil.
${ }^{9}$ Nos referimos al proyecto UBACyT

20020130200085BA “Jóvenes militantes y espacios juveniles en agrupaciones político partidarias: una aproximación a las formas de compromiso juvenil luego de la crisis de 2001", dirigido por Melina Vázquez y co-dirigido por Pablo Vommaro (UBA, 2014-2017).

${ }^{10}$ Las encuestas y las entrevistas fueron realizadas a militantes definidos desde los partidos como jóvenes, prescindiendo de criterios (etarios, por ejemplo) definidos por fuera del universo militante. De este modo se buscó evitar el uso de definiciones normativas. derm \& Wood 2013) y Latinoamericano (Castro Rocha 2009; Espinoza \& Madrid 2010; Acosta 2011; Brenner 2012; Lizbona 2012; Victal 2017). En el caso argentino fue abordado más tardíamente aunque en los últimos años se ha nutrido de nuevas investigaciones (Molinari 2010; Cozachcow 2015; Núñez \& Cozachcow 2016; Vázquez 2014; Vázquez \& Vommaro 2012; Vázquez \& Cozachcow, 2015; Grandinetti 2015; Mutuverría 2015). En este sentido, y de acuerdo con el enfoque escogido, proponemos una aproximación descriptiva a la militancia, apelando al uso de una herramienta relativamente poco trabajada en los estudios sobre activismo juvenil en Argentina, como son las encuestas a activistas.

El aporte del presente trabajo a los campos temáticos en los que se inserta tienen que ver, en primer lugar, con la posibilidad de analizar las relaciones entre la militancia juvenil y las gestiones de gobierno con el fin de explorar cómo, a la luz de esos vínculos, se construyen las maneras de entender los compromisos y los repertorios de acciones militantes. En segundo lugar, con indagar las mencionadas relaciones en gestiones de gobierno de partidos como los elegidos, dado que la indagación de las relaciones entre trabajo en el Estado y activismo juvenil ha sido objeto de estudios únicamente en relación con la gestión del Frente para la Victoria del Poder Ejecutivo Nacional, esto es, con los mandatos de Néstor Kirchner (2003-2007) y Cristina Fernández de Kirchner. La visibilidad pública de algunas de las organizaciones juveniles vinculadas con este espacio político llevaron a que la literatura académica se concentrara en estudiar puntualmente las organizaciones juveniles kirchneristas, concluyendo que las relaciones entre militancia y gestión se desprenden de propiedades específicas de dicho espacio político. Esto, a nuestro modo de ver, no permite identificar los elementos comunes que se pueden reconocer entre la revitalización de las juventudes en la militancia vinculada a partidos políticos y la gestión pública en diferentes espacios político partidarios, más allá de la orientación política de los mismos, así como del nivel de gobierno. En este sentido, la posibilidad de explorar las militancias en experiencias políticas de distinto color político en un mismo nivel en la gestión estatal que no es nacional, permite analizar la eventual configuración de (nuevas) figuras de militancia (Pudal 2011) en las cuales militancia y trabajo en el Estado aparecen como elementos centrales en el desarrollo de activismo juveniles en el contexto argentino actual.

Este escrito recoge algunos de los resultados de una investigación más amplia sobre la participación juvenil en partidos políticos en la Argentina ${ }^{9}$, en la que se incluyen, además, otras fuerzas políticas. En este trabajo recuperamos algunos de los resultados de la mencionada investigación, concretamente, entrevistas en profundidad a dirigentes y militantes juveniles ${ }^{10}$ con distintos niveles y modos de responsabilidad dentro de cada partido ${ }^{11}$; encuestas aplicadas con jóvenes de ambos partidos ${ }^{12}$ y observaciones participantes realizadas en instancias de reunión definidas como juveniles por parte de ambos partidos.

El artículo se organiza en diferentes apartados, a continuación presentamos los dos partidos escogidos para el análisis mostrando la historia de los mismos, el modo en que acceden a las gestiones de gobierno locales y la conformación de sus espacios juveniles. Luego realizamos una aproximación a los perfiles de las y los militantes jóvenes del PRO de la CABA y el PS de Santa Fe recuperando los resultados de las encuestas. Posteriormente, se analizan las configuraciones de sentido producidas en torno al vínculo entre gestión y militancia, retomando para ello tanto los resultados de las encuestas como los testimonios de los y las activistas. Exploramos, por un lado, el impacto que tiene el hecho de ser gestión para el activismo juvenil y, por el otro, los espacios de socialización militante en la formación de cuadros y carreras militantes. Finalmente, realizamos un balance de los modelos de militancia juvenil que emergen del análisis de los dos partidos y de las particulares conexiones que se esta- 
blecen entre militancia y gestión, explorando qué rasgos permiten pensar en la configuración de nuevos modelos de activismo.

\section{EI PS y el PRO: sociogénesis partidaria, las gestiones y los espacios juveniles}

\section{II.1. Sociogénesis partidaria y gestiones de gobierno}

${ }^{11}$ Se realizaron entrevistas biográficas individuales semi-estructuradas en las cuales se indagó por el background sociológico de los entrevistados, el proceso de ingreso a la militancia, las experiencias de militancia previas y contemporáneas entre familiares y conocidos, el desarrollo de una carrera dentro del partido y de gestión, las concepciones acerca del Estado, la militancia y la política.

${ }^{12}$ Se aplicaron 58 encuestas a militantes del PRO de la CABA (julio, 2013) y a militantes del PS de Santa Fe (enero, 2013). Las encuestas se organizan en ejes temáticos, estos son: perfiles sociodemográficos; trayectorias educativas, laborales y militantes (propias y de familiares); modos y sentidos que dan a la militancia y a la gestión; repertorios de acciones militantes; conocimiento de políticas públicas de juventud; caracterización de hechos históricos en Argentina.

${ }^{13}$ Es posible que el nuevo escenario modifique fuertemente al PRO, principal partido en la alianza Cambiemos. Dichos cambios, impactarán en su funcionamiento y en los modos de militancia, en general. Advertimos sobre este punto aún cuando no podemos tener registro todavía de los mencionados impactos

${ }^{14} \mathrm{Si}$ en el siglo XX en Argentina las fuerzas de derecha buscaron conquistar el poder por medio de vías no electorales, el PRO muestra la búsqueda por construir un discurso democrático y un modo de acceso al poder vinculado a la competencia electoral que con promover la inserción de cuadros en gobiernos de otros partidos (Vommaro, Morresi \& Bellotti 2015).

${ }^{15}$ Estas definiciones se pueden encontrar en el prólogo
El PS posee una tradición centenaria dentro del socialismo argentino, puesto que fue fundado en 1896. Actualmente el partido lidera una coalición denominada Frente Progresista Cívico y Social que gobierna la Provincia de Santa Fe desde el año 2007 y la Ciudad de Rosario desde 1989. Por su parte, el PRO, se crea en el año 2002 en la CABA y gobierna desde el año 2007 el distrito. Para las elecciones nacionales de 2015 el partido impulsa la creación de la alianza "Cambiemos", junto a la UCR y la Coalición Cívica, con la que Mauricio Macri accede a la Presidencia de la Nación (2015-2019) luego de un ballotage. El PRO también obtiene la Gobernación de Provincia de Buenos Aires (la más poblada del país), y un conjunto de Municipios de la misma Provincia. ${ }^{13}$

En cuanto a la dimensión ideológica, el PS es un partido liberal de centroizquierda, mientras que el PRO puede caracterizarse como una suerte de partido de la nueva derecha democrática ${ }^{14}$. Aunque el continuo izquierda-derecha no es el único ni, tal vez, el principal clivaje por el que se tramitan las identificaciones políticas en la Argentina, el mismo resulta significativo para poder distinguir a ambos partidos teniendo en cuenta las diferentes visiones que sostienen en cada espacio en relación con el Estado, la gestión de lo público y otros aspectos centrales para analizar las configuraciones de sentido entre militancia y gestión. De acuerdo con lo dicho, mientras que el PS se autodefine como la izquierda democrática, postulando una interpretación reformista de la tradición marxista-leninista y de los vínculos entre socialismo y democracia, el PRO se postula más allá de la dicotomía izquierda-derecha, postulando el pragmatismo como valor central, asociado a un conjunto de valores posmateriales, aunque las posturas de sus dirigentes frente a ciertas temáticas lo ubican a la derecha del espectro ideológico (Vommaro \& Morresi 2015).

Un elemento constitutivo de ambas narrativas partidarias es el desempeño en la gestión pública, sin embargo se reconocen diferentes tematizaciones de las mismas en uno y otro partido. En el PRO se observa una concepción de la gestión orientada un saber técnico asociado a esa concepción pragmatista de la política, en la cual la crisis de representación es leída como aquello que favorece el ingreso a la política (Offerlé 1998) por parte de un conjunto de personas desvinculadas de la misma, siendo precisamente esta marca de origen aquello en torno a lo cual se construye el capital político de sus dirigentes.

En el caso del PS, se reconoce una concepción de la política y el Estado orientada a la ampliación de derechos, postulando la eficiencia, la trasparencia, la promoción de la participación y la reducción de las desigualdades, como elementos centrales de la gestión de gobierno ${ }^{15}$. Otro elemento fundamental en la narrativa oficial partidaria tiene que ver con la idea de novedad y el modo en que se busca renovar las prácticas políticas. En este sentido, la perspectiva joven en la construcción de las políticas públicas, a partir de la innovadora experiencia del Gabinete Joven -que será abordada más adelante-, aparece como otro aspecto central de la gestión, que combina la apelación a lo nuevo con tradiciones centenarias.

Hasta aquí, como se desprende de las anteriores caracterizaciones, las diferencias entre los partidos son enormes. Ahora bien, ambos acceden a las gestiones de Santa Fe y de la CABA, respectivamente, en el año 2007 y en un contexto en el que se ha observa en la Argentina una revitalización de los 
del entonces Gobernador de Santa Fé, Hermes Binner en un documento elaborado por la Fundación Friedich Ebert (Reyna \& Rigat-Pflaum 2009) titulado "Santa Fe, una nueva gestión en la política". vínculos entre jóvenes y partidos políticos. No solamente esto, sino que en ambos casos los espacios juveniles de los partidos se ven fuertemente influidos por dicho proceso. Vemos así que pese a las diferencias que se reconocen en cuanto a los perfiles ideológicos y las trayectorias de cada partido, en ambos casos se observa un marcado crecimiento de la presencia de militantes jóvenes, así como también la incorporación de una narrativa juvenil a la discursividad pública de sus principales dirigentes, cuestiones sobre las que trabajamos en el próximo apartado.

\section{II.2. Los espacios juveniles del PS y el PRO frente al proceso de movilización política juvenil}

A continuación proponemos caracterizar brevemente los espacios juveniles de ambos partidos atendiendo a la historia de su creación como también a las configuraciones de las actuales modalidades de reclutamiento y los modos en que promocionan la participación juvenil. Esta breve caracterización nos permitirá dar cuenta de un proceso de movilización política juvenil caracterizado por la orientación del activismo juvenil hacia el Estado y las instituciones de la democracia representativa y el ámbito político partidario.

En este apartado realizamos una breve reconstrucción del surgimiento de cada espacio político así como del momento y la manera en que comienza a crearse un espacio diferenciado de juventud siguiendo algunas de las premisas del enfoque sociohistórico, el cual propone hacer un tratamiento sociológico de los objetos políticos. De acuerdo con esta perspectiva podremos notar que la militancia juvenil en el caso del socialismo santafesino es construida fuertemente en torno al activismo estudiantil en la universidad pública. Más concretamente, la militancia partidaria es vista como una extensión de la participación en el movimiento estudiantil universitario. En el caso del PRO, al tratarse de un partido nuevo que se consolida fuertemente durante el acceso a la gestión gubernamental, la militancia juvenil se conforma en torno a discursos que valorizan saberes técnicos profesionales que requieren ciertos niveles de formación universitaria, al mismo tiempo que la condición juvenil es valorizada a partir de una concepción de cambio de la que el partido busca presentarse como cabal expresión.

La tradición del socialismo argentino es de raigambre reformista y socialdemócrata ${ }^{16}$. Desde su conformación se han producido múltiples divisiones y reagrupamientos. La trayectoria de uno de estos grupos, el Movimiento Nacional Reformista (MNR), permite comprender la conformación de la línea interna que hegemoniza actualmente el PS, referenciada en el ex Gobernador Hermes Binner. El MNR se crea en 1960 como una organización del movimiento estudiantil universitario en la Provincia de Santa Fe a partir del liderazgo de Guillermo Estévez Boero -presidente de la Federación Universitaria Argentina en 1959- y deriva en la creación del Partido Socialista Popular (PSP) en 1972. Este partido tiene su primera experiencia en la gestión en el año 1989, en Rosario. Tras el retorno a la democracia en 1983, el PSP actúa en conjunto con otro de los principales partidos socialistas -el Partido Socialista Democrático (PSD)- aunque manteniendo estructuras separadas hasta el año 2002, cuando ambos partidos se fusionan conformando el actual PS. Si bien los espacios juveniles de ambos realizan durante los años ochentas y los noventas actividades conjuntas, la organización de los campamentos juveniles en el primero es, tal vez, la actividad más significativa de juventud. Los mismos se organizan de forma ininterrumpida desde el año 1989 y son vistos como la instancia más importante de formación política entre los y las militantes socialistas.

Son dos los ámbitos de participación juvenil dentro del partido, ambos institucionalizados en la carta orgánica a nivel nacional: la Juventud Socialista (JS), esto es, el espacio juvenil del partido en el que confluyen los afiliados al 
partido entre 14 y 30 años y el Movimiento Nacional Reformista (MNR), del cual participan estudiantes universitarios, que pueden estar afiliados al partido, o no. La agrupación estudiantil ha tenido históricamente un papel fundamental en el reclutamiento partidario, en la socialización de sus militantes y en la formación de cuadros dirigenciales y ha establecido la conformación de su estructura nacional luego de la reunificación partidaria. Cada rama tiene su mesa nacional, con dos representantes por Provincia, que se reúne varias veces por año y elige Secretario General, cuyo mandato es de dos años de duración. Los Secretarios Generales participan con voz y voto de la Mesa Nacional del PS. A su vez, esta estructura se replica a nivel Provincial, siendo la organización del partido y de los espacios juveniles, de carácter federal. En ese sentido, nos encontramos con un espacio juvenil articulado de modo formal en el seno de un partido estructurado orgánicamente y con líneas internas definidas en función de los principales liderazgos a nivel provincial, aunque con un predominio de los miembros de la Provincia de Santa Fe. De acuerdo con entrevistas realizadas, la JS nacional se revitaliza a partir del año 2010, con la conformación de una mesa con representantes de todas las federaciones provinciales, y la realización de un primer congreso nacional en el año 2016.

Por su parte, el espacio juvenil del PRO en la CABA se crea de modo simultáneo a la conformación del partido, proceso que se replica a nivel nacional. Al igual que en el caso del PS, se encuentra reconocido en la carta orgánica del partido, tanto a nivel nacional como distrital para la Ciudad de Buenos Aires (CABA). El PRO se crea en el año 2003 con la denominación Compromiso Para el Cambio y participa en las elecciones en la Ciudad de Buenos Aires, obteniendo un importante número de miembros del poder legislativo de la Ciudad. En ese contexto, se conforma un pequeño grupo juvenil denominado Identidad. Tal como señala Grandinetti (2015), este es el grupo que lidera la posterior construcción de un espacio denominado Jóvenes PRO tras el triunfo del partido en la Jefatura de la Ciudad de Buenos Aires en el año 2007. Esa organización es la que se constituye en el espacio orgánico de la juventud del PRO en la CABA, aunque por la dinámica interna, incluye en su interior diferentes organizaciones juveniles del partido. Estas se distinguen en función de los referentes adultos a los que siguen, siendo todos ellos altos funcionarios en la gestión pública. En ese sentido, al momento de aplicar la encuesta, JPRO funcionaba como una suerte de federación de espacios juveniles del PRO, aunque también existen otras agrupaciones que no forman parte de la orgánica.

En cuanto a la organización interna, JPRO cuenta con un esquema de Secretarías y Subsecretarías de trabajo relacionadas con temas tales como: política universitaria, formación política, análisis y políticas públicas, organización política, acción social, ambiente, cultura y deportes y nuevos medios. La inserción en el ámbito universitario se da, centralmente, por medio de la Secretaría de Política Universitaria, que posee desarrollo en la Universidad de Buenos Aires (UBA), especialmente en la Facultad de Derecho y en algunas Universidades privadas y confesionales, como la Universidad Católica Argentina (UCA).

La elección de autoridades se define con base en las relaciones de fuerza de los sectores internos del partido -con injerencia de los liderazgos adultos-, a partir de las cuales se dan acuerdos entre las organizaciones que la integran. Las actividades que realiza la agrupación varían fuertemente en función de las campañas electorales. En los años que no son electorales, se destacan más las actividades de formación y de consolidación de los grupos de militantes, mientras que en los años electorales, la agrupación participa activamente en las actividades de la campaña y en otras que buscan dar visibilidad a la agrupación como festivales o encuentros para militantes. 


\section{Una aproximación a los perfiles de las y los militantes jóvenes del PRO en la CABA y del PS en Santa Fe}

A diferencia de las perspectivas que abordan esta cuestión tomando como punto de partida las definiciones políticas de los grupos como si fueran unidades homogéneas, aquí proponemos mostrar quiénes son los y las activistas y las diversas maneras en que tramitan sus compromisos al interior de cada uno de los espacios partidarios, así como el modo en que se configuran las carreras militantes (Fillieule 2015). Para ello haremos, a continuación, una presentación de las propiedades sociodemográficas de los y las activistas, de sus perfiles laborales y educativos, de los modos de participación dentro del partido y, finalmente, realizamos una descripción general de las carreras militantes.

\section{III.1. Lugares de procedencia, características sociodemográficas, estudio y trabajo}

Un primer aspecto a señalar en relación con la composición de las muestras con las que trabajamos es que los y las jóvenes que encuestamos en ambos partidos pertenecen fundamentalmente a grandes centros urbanos. En el caso de del PRO, el $88 \%$ es de la CABA y el 12\% de la Provincia de Buenos Aires, mientras que en el socialismo son, principalmente, de las ciudades de Rosario (64\%) y Santa Fe (21\%). Luego, y en menor medida, de ciudades medianas y pueblos del interior provincial (15\%). En relación con la distribución por género, el 53\% de los encuestados del socialismo son varones y el $45 \%$ son mujeres. En el caso del PRO, la cantidad de activistas jóvenes varones (66\%) es un poco más del doble de la cantidad de activistas mujeres (31\% ${ }^{17}$. En ambos espacios encontramos distribuciones similares en cuanto a la edad: las y los encuestados tienen una edad promedio de 24 años, siendo la franja de edad que va de los 19 a los 24 años aquella en la que se encuentra la mitad de los activistas juveniles, tanto del socialismo como del PRO. A este grupo etario le sigue el de aquellos que tienen entre 25 y 30 años, que representa el $43 \%$ de las y los encuestados en cada partido.

En segundo término, los resultados de la encuesta (véanse las Tablas 1 y 2) como del trabajo de campo en general, permiten destacar el perfil marcadamente estudiantil de las y los militantes jóvenes de ambos partidos, tal es así que el $83 \%$ de los activistas del socialismo y el $81 \%$ de los militantes juveniles del PRO son estudiantes actualmente. Entre estos, se observa una marcada presencia de estudiantes de nivel superior (el 88,6\% de los militantes socialistas y el $85 \%$ de los militantes del PRO). En cuanto a la situación laboral, el $78 \%$ de los encuestados del PRO trabaja, mientras que un $22 \%$ no lo hace. En el caso de los socialistas santafesinos, trabaja el $56,6 \%$, mientras que un $34 \%$ señala no trabajar.

Tabla 1 - Participantes que estudian y/o trabajan de encuesta a militantes del PS de Santa Fé, 24 Campamento Nacional de la JS, Enero 2013 (\%)

\begin{tabular}{lccccc}
\hline & & \multicolumn{3}{c}{ Trabajo } & Total \\
\cline { 3 - 5 } & & $\mathbf{S i}$ & No & Sin Datos & \\
\hline Estudio & $\mathrm{Si}$ & 41,5 & 34,0 & 7,5 & 83,0 \\
& No & 11,3 & - & - & 11,3 \\
Sin Datos & & 3,8 & - & 1,9 & 5,7 \\
Total & & 56,6 & 34,0 & 9,4 & 100,0 \\
\hline
\end{tabular}

Fuente: Elaboración propia.

$\mathrm{N}=53$. 
Tabla 2 - Participantes que estudian y/o trabajan de encuesta a militantes del PRO en la CABA, Julio de $2013(\%)$

\begin{tabular}{lcccc}
\hline & & \multicolumn{2}{c}{ Trabajo } & \multirow{2}{*}{ Total } \\
\cline { 3 - 4 } & & Si & No & \\
\hline Estudio & Si & 60,3 & 20,7 & 81,0 \\
& No & 17,2 & 1,7 & 19,0 \\
Total & & 77,6 & 22,4 & 100,0 \\
\hline
\end{tabular}

Fuente: Elaboración propia.

Nota: $\mathrm{N}=58$.

Si cruzamos los datos de estudio y trabajo observamos que el porcentaje de aquellos que estudian y trabajan es mayor en el PRO (60\%) que en el PS (41\%), mientras que al observar los porcentajes de las y los que estudian pero no trabajan encontramos que la proporción de los socialistas es ligeramente mayor (34\%) que los del PRO (21\%). Como se desprende del trabajo de campo realizado, podemos aventurar que la menor proporción de jóvenes militantes que trabajan en el caso del socialismo obedece a una dilación en el ingreso al trabajo asociada con el hecho de priorizar la finalización de los estudios universitarios. Es habitual entre la militancia socialista identificar desplazamientos desde los pueblos del interior de la Provincia de Santa Fe a Rosario, centralmente, con el objetivo de realizar estudios universitarios.

\section{III.2. Recorridos y carreras militantes}

${ }^{18}$ En estos casos se trata de activistas que participan de los espacios juveniles pero que, al momento de explicitar el modo de participar dentro del partido, sitúan su inscripción por fuera de los ámbitos juveniles propiamente dichos. ${ }^{19} \mathrm{Si}$ bien no es el nombre de una agrupación interna, los encuestados respondieron de esa manera, evidenciando el vínculo con algún área de la Fundación Pensar, think tank del PRO que cuenta con espacios donde participan jóvenes.
Las y los jóvenes encuestados del socialismo participan fundamentalmente en dos de los espacios definidos en la carta orgánica del PS: el MNR (51\%) y la JS (26\%), así como también hay quienes militan directamente en el partido $(23 \%)^{18}$. En el PRO, se observa una manera más compleja de definir las vinculaciones con el partido: mientras que casi la mitad (47\%) afirma que participa tanto en el PRO (26\%) como en la Juventud del PRO (21\%), propiamente dicha, la otra mitad (50\%) hace alusión a su vinculación con el partido a partir de su inscripción en el espacio juvenil de diferentes líneas internas. El 22,5\% participa del Juventud Proyección Federal, el 8,6\% de La corriente, el $3,4 \%$ de Pensar Política ${ }^{19}$ el 3,4\% de La 24, el 3,4\% de Renovación Ciudadana, entre otras de las líneas y agrupamientos internos mencionados.

Más allá de los espacios internos en los que militan actualmente las y los jóvenes activistas, es interesante observar, como se muestra en el los Gráficos 1 y 2, que la militancia en los mencionados partidos constituye la primera experiencia de militancia para el $93 \%$ de las personas encuestadas del PRO de la CABA y para el $91 \%$ de las del PS de Santa Fe. En otros términos, sólo el 7\% y el 9\%, respectivamente, poseen experiencias previas de militancia por fuera de estos partidos.

Si observamos el año en el que comenzamos a militar los activistas tanto en el Socialismo como en el PRO (véanse Gráficos 3 y 4 a continuación), se pueden destacar dos cuestiones. Por un lado, y de modo coincidente con otras investigaciones sobre militancia partidaria realizadas desde este enfoque, observamos que los años en los que tienen lugar campañas electorales se produce un incremento de la participación juvenil. Según Bargel y Petitfils (2009, apud Franz 2016), las campañas electorales representan momentos privilegiados para (re)activar vínculos partidarios así como también para construir sentimientos de pertenencia a un espacio partidario. En este sentido, por otro lado, notamos la importancia que poseen aquellos años en los que participan de 
Gráfico 1 - Participantes que iniciaron su militancia en espacios del PS. Militantes del PS de Santa Fé

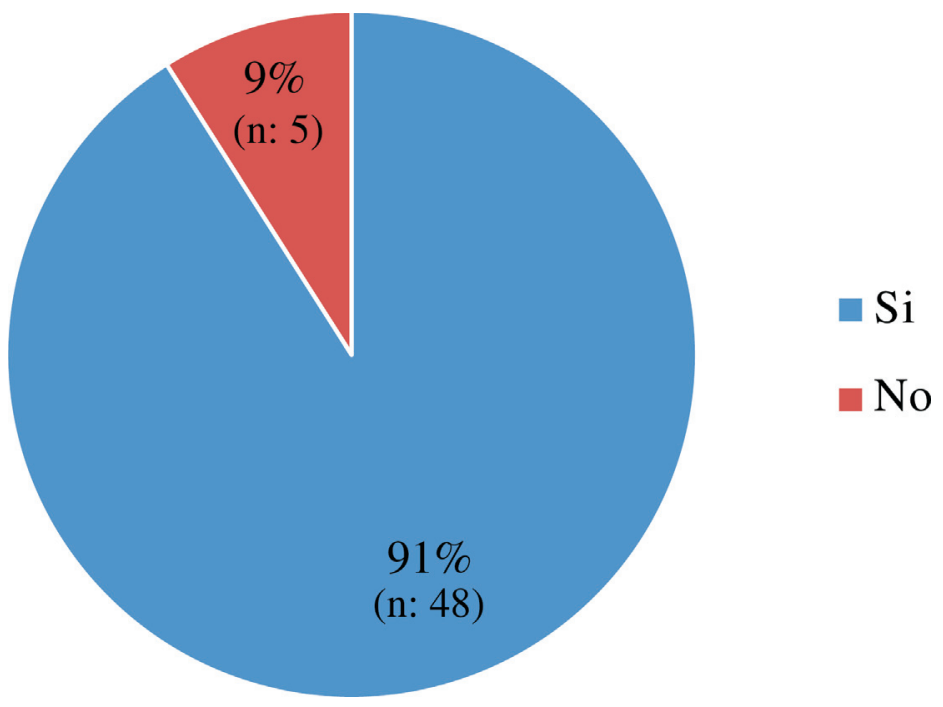

Fuente: Elaboración propia.

Nota: $\mathrm{N}=53$.

Gráfico 2 - Participantes que iniciaron su militancia en el PRO. Militantes del PRO en la CABA

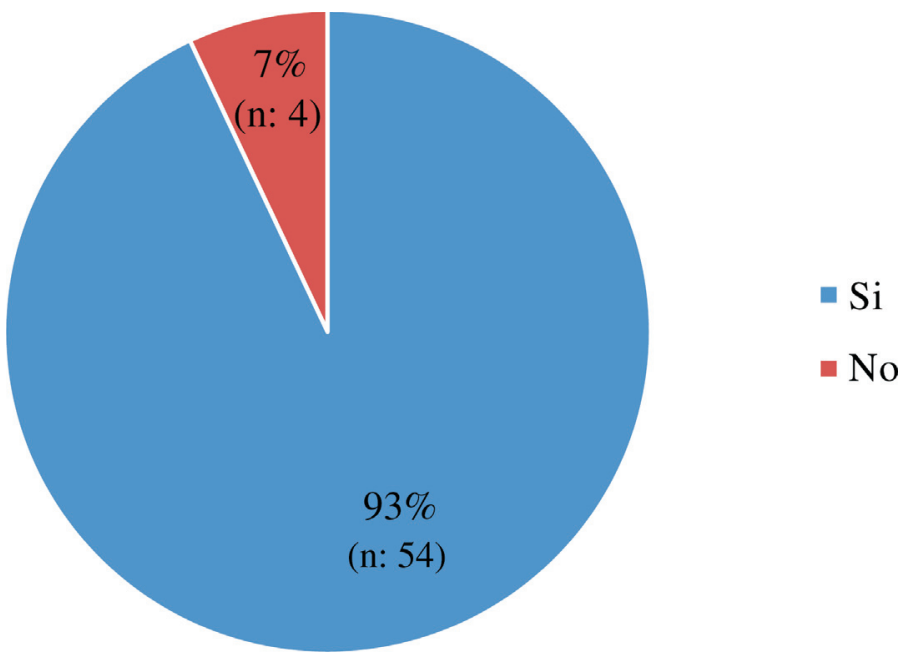

Fuente: Elaboración propia.

Nota: $\mathrm{N}=58$.

la competencia electoral Binner (en 2007 como candidato a la Gobernación de la Provincia de Santa Fe y en 2011 como candidato a Presidente de la Nación) en el caso del socialismo y de la candidatura de Macri en el año 2011, cuando se presenta como candidato para ser reelegido Jefe de Gobierno de la CABA.

De acuerdo con lo dicho, observamos que las y los militantes jóvenes de ambas organizaciones inician su militancia en los mismos partidos en los que actualmente participan. Esto no quiere decir que no se observen desplazamientos al interior de los espacios partidarios, sino más bien que el inicio y el desarrollo de sus carreras militantes se da íntegramente dentro de los partidos, 
Gráfico 3 - Año de inicio en la militancia de jóvenes del PS de Santa Fe que empezaron a militar en el socialismo

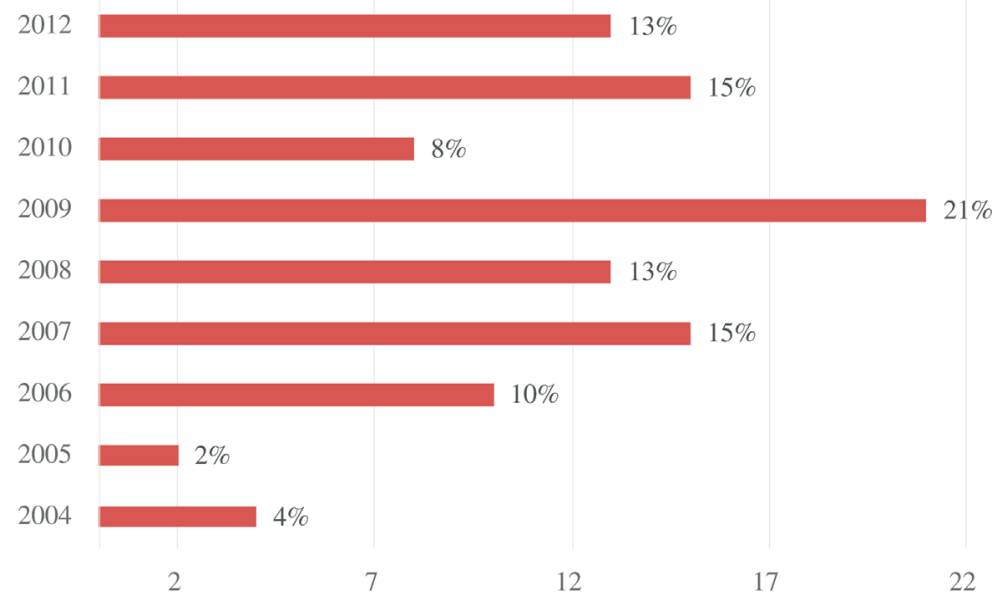

Fuente: Elaboración propia Nota: $\mathrm{N}=48$.

Gráfico 4 - Año de inicio en la militancia de jóvenes del PRO de la CABA que empezaron a militar en el partido

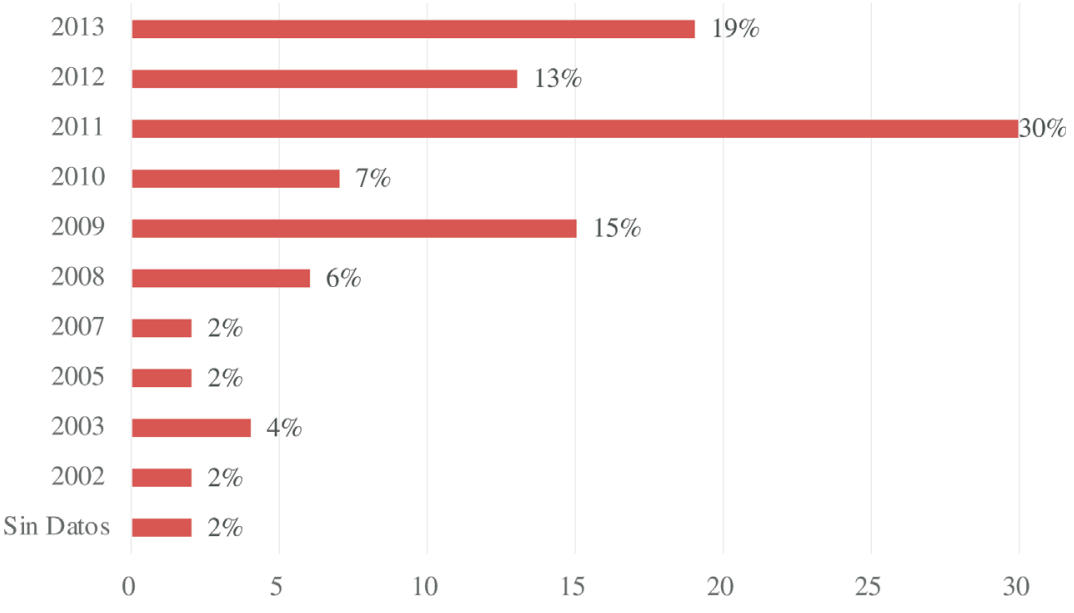

Fuente: Elaboración propia.

Nota: $\mathrm{N}=54$.

en especial en el caso del socialismo, en el que la mitad de las y los activistas juveniles se inician por medio del MNR.

Finalmente, cabe destacar que el $85 \%$ del PS y el 92\% del PRO ingresan a la militancia una vez que los partidos forman parte de gestiones de gobierno a nivel subnacional. Esto es fundamental para poder abordar, a continuación, las relaciones que tejen las y los militantes entre activismo, gestión estatal y la inserción de los mismos al trabajo en el Estado.

\section{Sentidos y vínculos entre la gestión y la militancia}

Luego de una primera aproximación a los perfiles de los y las jóvenes militantes de ambos partidos, nos enfocamos en el análisis de las relaciones entre activismo y gestión a partir de tres ejes analíticos que surgen del trabajo de campo y que permiten reponer un conjunto de dimensiones relevantes para el 
estudio de las carreras militantes. En primer lugar, abordamos las relaciones entre formación y militancia; en segundo lugar las relaciones entre activismo y trabajo en la gestión pública; y en tercer lugar analizamos los espacios de socialización militante en la formación de cuadros y carreras militantes.

\section{IV.1 Relaciones entre formación académica y activismo}

${ }^{20}$ En el año 2017 el MNR tiene a su cargo la mitad de los Centros de Estudiantes, así como la Federación

Universitaria de Rosario.
En el socialismo santafesino, la militancia juvenil aparece fuertemente entrelazada con la universidad pública. Esto se puede observar -como se mencionó anteriormente- en la relevancia que adquieren los estudiantes universitarios entre las y los encuestados así como también en el perfil de los dirigentes adultos, que en su mayoría fueron estudiantes y dirigentes universitarios del MNR. Cómo se muestra en el Gráfico 5, las y los activistas provienen, además, de aquellas carreras universitarias en las que el MNR posee mayor presencia en las dos principales universidades de la provincia: la Universidad Nacional de Rosario (UNR) ${ }^{20}$ y la Universidad Nacional del Litoral (UNL) de la ciudad de Santa Fe. Concretamente, el 25,6\% estudia Arquitectura, el 20,5\% Derecho, el 12,8\% Ciencias Políticas o Relaciones Internacionales, el $10,3 \%$ carreras vinculadas a las ciencias exactas y naturales y el 10,3\% medicina.

En el caso del PRO, la presencia significativa de estudiantes universitarios obedece más bien a la centralidad que poseen las redes de relaciones y las lógicas de reclutamiento partidario en ámbitos específicos como son las Universidades privadas confesionales, cuestión que ha sido señalada en la literatura especializada sobre el PRO (Grandinetti 2015; Vommaro \& Morresi 2015; Vommaro Morresi \& Belloti 2015).

Resulta interesante notar que en este universo de militantes, las carreras de las que provienen son, centralmente, Derecho (el 43\%) y Ciencia Política o Relaciones internacionales (26\%), como podemos observar en el Gráfico 6 a continuación.

Uno de los principales ámbitos de reclutamiento partidario entre las y los activistas del PRO de la CABA son las universidades privadas de corte confesional: la Universidad del Salvador (USAL) y la Universidad Católica Argentina (UCA). En estas casas de estudio se formaron, por ejemplo, tres de los ex

Gráfico 5 - Distribución por carreras de jóvenes del PS de Santa Fe que estudian en el nivel universitario

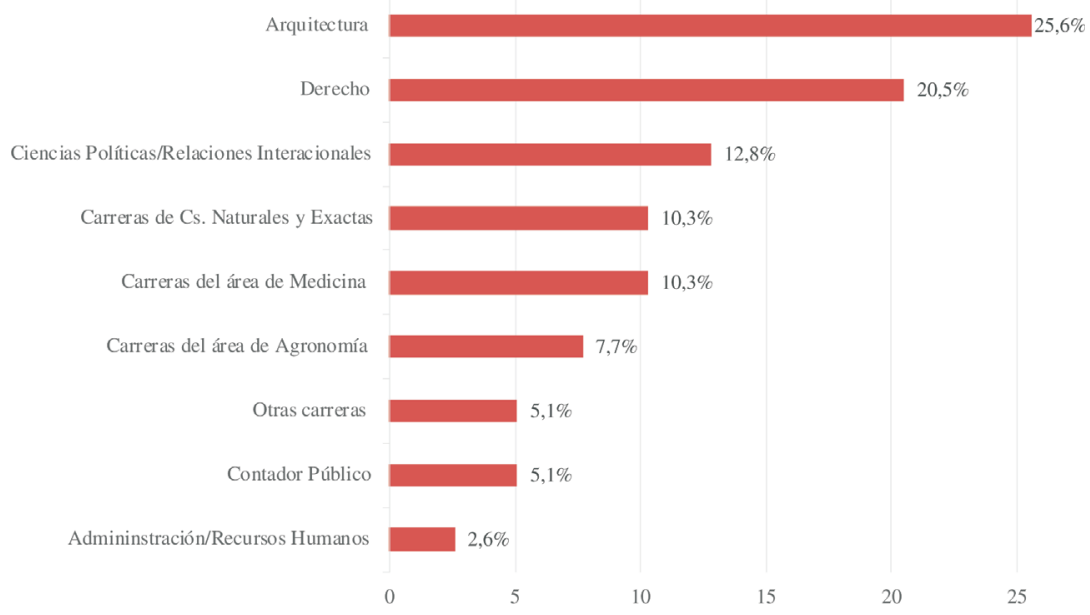

Fuente: Elaboración propia.

Nota: $\mathrm{N}=39$. 
Gráfico 6 - Distribución por carreras de jóvenes del PRO de la CABA que estudian en el nivel universitario

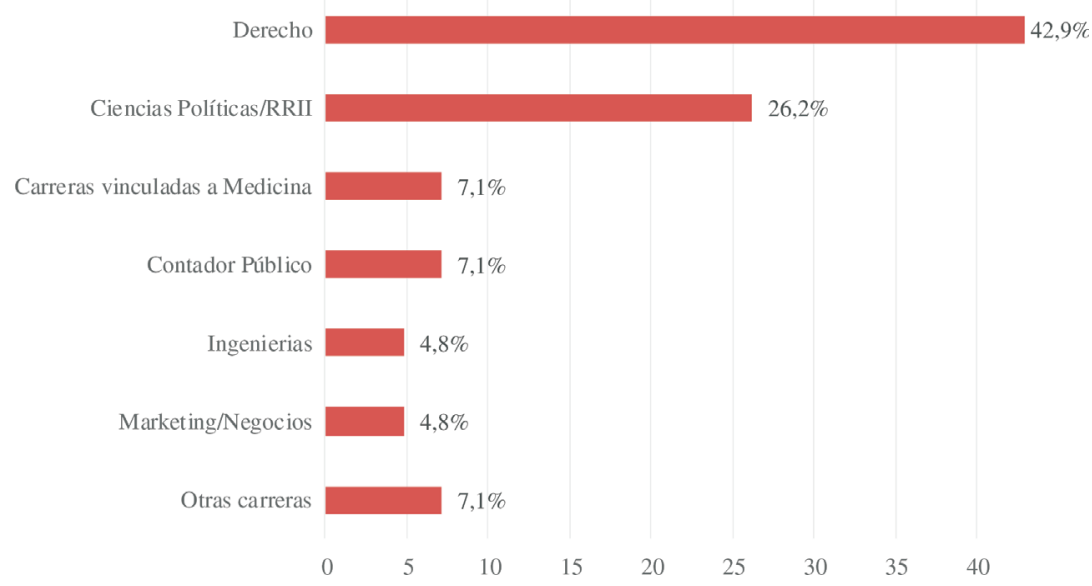

Fuente: Elaboración propia.

Nota: $\mathrm{N}=42$.

${ }^{21}$ En el cuestionario que se aplicó con las y los militantes se incluyeron preguntas sobre la situación laboral de los encuestados y se preguntó, además, si se desempeñaban en un cargo público o en algún cargo partidario. En ninguno de los casos, y de modo intencional, se hizo una caracterización previa acerca de qué queríamos decir por cargo público o partidario. presidentes de Jóvenes PRO de la CABA entre los años 2009 y 2013, quienes actualmente ocupan responsabilidades de mayor jerarquía tanto en el Poder Ejecutivo como Legislativo de la CABA. Por otra parte, hay un incipiente desarrollo de organizaciones estudiantiles en algunas facultades de la UBA.

Ahora bien, más allá de la incidencia de cada partido en un perfil o tipo de Universidad (pública o privada), vale la pena destacar es la relación entre la carrera que estudian y la militancia. Como se desprende del trabajo de campo realizado, hay un conjunto de saberes vinculados con la formación universitaria en ciertas carreras (como las de Derecho, Ciencias Políticas y Relaciones Internacionales) que son considerados valiosos entre las y los activistas que no solamente militan en un espacio partidario sino que además se desempeñan en gran parte como trabajadores y/o empleados públicos vinculados con las gestiones de gobierno. En efecto, el 19\% de las y los jóvenes socialistas santafesinos y $36 \%$ entre las y los jóvenes del PRO trabajan en la gestión, mientras que el 63\% en el PS y el 80\% en el PRO, aspira a tener un cargo público en la gestión a futuro, como mostramos en el próximo apartado ${ }^{21}$.

Vemos, así, que la condición estudiantil de nivel superior de las y los activistas y su vinculación con carreras específicas supone no solamente que el espacio universitario sea un ámbito de reclutamiento militante de activistas, sino además que hay un conjunto de conocimientos adquiridos en la formación universitaria que son recuperados y valorados en el desempeño militante de las y los jóvenes. En otras palabras, el saber adquirido en el campo académicouniversitario parece susceptible de ser reconvertido en otros campos entrelazados: el político y el burocrático-administrativo.

En el caso del Partido Socialista, las interrelaciones entre este entorno partidario particular y la militancia partidaria propiamente dicha reconocen algunas particularidades más. La universidad como ámbito social y espacio de prestigio cobra especial relevancia en la construcción de una narrativa y una historia común entre los militantes socialistas, aspecto que se evidencia en el perfil de sus referentes políticos en la historia del partido, en los principales hitos en los que se elabora la narrativa histórica del mismo y en los símbolos en los que se reconocen y producen una unidad común. 
IV.2. Activismo y trabajo en la gestión pública

${ }^{22}$ La relación entre trabajo y militancia no puede acotarse solamente al Estado para el caso del PRO, puesto que en este partido el trabajo en el ámbito privado representa un espacio de reclutamiento entre militantes y funcionarios, al mismo tiempo que dentro del partido representa un capital militante.
Uno de los aspectos que nos interesaba explorar con la implementación de las encuestas a militantes tenía que ver con conocer la situación laboral así como de qué modo se ponen en relación las carreras militantes y las carreras laborales. Partiendo del hecho de que ambos partidos tienen bajo su responsabilidad la gestión estatal a nivel local o provincial, nos propusimos desentrañar las relaciones entre el compromiso político y militante (las condiciones de ingreso, ascenso o incluso de salida) y el desarrollo de carreras laborales con las que la militancia se articula de distintas maneras. No solamente nos interesaba observar estos desplazamientos, sino también en qué medida trabajar en el Estado se construye como parte de las expectativas de las y los activistas, cuáles son los sentidos que atribuyen a militar y trabajar en el Estado, así como también si hay un correlato entre el desarrollo de carreras militantes y laborales exitosas.

Como ya hemos señalado, el porcentaje de militantes que trabajan es elevado en ambos partidos: el 78\% del PRO y el 56,6\% del PS. Ahora bien, en este apartado proponemos describir con mayor detenimiento la inserción laboral de las y los jóvenes activistas, postulando relaciones con los sentidos que construyen en torno a su desempeño como trabajadores en el Estado y la militancia propiamente dicha.

El 36\% de las y los encuestados del PRO de la CABA afirma que trabaja en alguno de los poderes de la Ciudad, fundamentalmente el Ejecutivo. Del $42 \%$ restante que trabaja, el $14 \%$ lo hace en el sector privado ${ }^{22}$, el $26,2 \%$ no especifica en qué ámbito trabaja y el 1,8\% menciona que el partido es su espacio laboral. En el caso del PS de Santa Fe, el 19\% trabaja en los Poderes Ejecutivos de la Provincia de Santa Fe, la Ciudad de Rosario o la Ciudad de Santa Fe. Del $37,6 \%$ restante que trabaja, el $19 \%$ lo hace en el ámbito privado, el 16,8\% no especifica ámbito de trabajo y el 1,8\% menciona al partido.

En síntesis, y de acuerdo con lo dicho, aunque con porcentajes diferentes, en ambos partidos podemos reconocer la presencia de militantes que trabajan en el Estado en la escala provincial y/o municipal en la que el partido de pertenencia es gestión.

Si además de esta información, reponemos las respuestas que los activistas dieron acerca de si tienen cargos públicos y partidarios, podemos identificar nuevas e interesantes diferencias. Las y los militantes del PRO que trabajan en el Estado representan un $36 \%$ del total de los encuestados, sin embargo solamente el 14\% manifiesta tener un cargo público, entre los cuales encontramos asesores, empleados administrativos, responsables de personal y algunos que no mencionan qué tipo de cargo ocupan.

En el caso del PS, se observa una situación inversa: el 19\% señala que trabaja en el Estado, pero el $26 \%$ sostiene que posee un cargo público. Entre quienes sostienen que poseen un cargo público pero que no trabajan en el Estado encontramos personas con roles vinculados con el desarrollo de una política pública, tareas de asesoramiento a Legisladores, Consejeros Directivos en Facultades, docentes, personas con distintos tipos de trabajos en la Gobernación y hay quienes no responden qué tipo de cargo desempeñan. Vemos así que en el caso del PS la noción de cargo público reconoce una heterogeneidad de sentidos mucho mayor que en el caso del PRO, al mismo tiempo que esta noción trasciende tanto el trabajo en el Estado como los cargos vinculados a la gestión, otorgando al sentido de lo público una noción más amplia que entre los encuestados del PRO.

En cuanto a las responsabilidades al interior de los partidos, en ambos casos más del $75 \%$ señala que no ocupa cargos partidarios. En el socialismo, el $21 \%$ 
${ }^{23}$ En estos se reconocen dos itinerarios diferentes: el ingreso al trabajo en el Estado desde agrupaciones afines al kirchnerismo (Vázquez y Vommaro 2012) y la gestación de compromisos definidos en términos militantes en el marco del desarrollo de una actividad laboral en el Estado que deriva en la creación de agrupaciones entre los propios trabajadores y funcionarios de un área (Vázquez 2014; 2015).

${ }^{24} \mathrm{La}$ literatura que analizó las relaciones entre militancia y trabajo en el Estado durante los gobiernos kirchneristas señala el peso significativo que guarda el Estado como espacio de consagración de carreras y grupos militantes (Perelmiter 2010; 2011).

${ }^{25}$ Los nombres de los entrevistados son cambiados para preservar su identidad.
${ }^{26}$ La ciudad de Rosario se menciona que ocupa cargos partidarios, mientras que en el PRO, lo hace un $17 \%$.

En el caso del socialismo se puede ver, de modo similar a algunos de los espacios juveniles vinculados al kirchnerismo ${ }^{23}$ y como contrapunto de las juventudes del PRO, el hecho de que el ingreso al Estado en calidad de miembro de una agrupación o activista es vivido como un reconocimiento militante ${ }^{24}$. En otros términos, el trabajo en el Estado aparece como instancia posterior a un reconocimiento o legitimación militante. Asimismo, el trabajo en la gestión por parte de los militantes es visto como una suerte de garantía en el impulso de acciones tendientes a mejorar las poblaciones destinatarias de diferentes programas y planes. En este sentido, la presencia de militantes juveniles es leída como elemento positivo para el impulso, el reconocimiento y la construcción de la juventud como un tema de agenda en la gestión.

Este es, por ejemplo, el caso de Martín ${ }^{25}$ (29 años, rosarino, dirigente juvenil en los grupos del socialismo que realizan tareas de activismo territorial en los barrios de Rosario y trabajador en el área de Presupuesto Participativo de la Municipalidad de Rosario, entrevistado en Julio de 2014) quien, al igual que buena parte de la militancia juvenil socialista, hizo su primer acercamiento al partido en la universidad pública, para luego encontrar su espacio de militancia en el trabajo territorial en las zonas más vulnerables de Rosario. Esta actividad militante luego se materializó en el trabajo en el Estado en el marco de la implementación de un Programa gubernamental fuertemente relacionado con una dinámica participativa en la que cobran centralidad las organizaciones territoriales. En este sentido, el pasaje del barrio al Estado en su carrera militante es vivido en una solución de continuidad. Sin embargo, la posibilidad de trabajar en el primero es destacada por ser vista como una vía para impulsar, concretar y llevar adelante aspectos que -desde su punto de vista- se relacionan con un proceso de cambio social que no puede ser alcanzado solamente desde la militancia territorial.

Además, para Martín y para una parte importante de la actual militancia juvenil del socialismo, el Estado es visto como un espacio central para garantizar la participación en la medida en que la gestión estatal de las necesidades es aquella que genera condiciones de posibilidad para la primera. Como sostiene el entrevistado:

"Para nosotros la sociedad se cambia a partir de la participación, que es un elemento clave. Entonces en la medida en que un joven entienda que es importante involucrarse en la actividad que hace -ya sea en el club, en la escuela, donde trabaje, o donde esté, en su ámbito- pueda involucrarse para mejorar el ámbito donde está (...) pero a veces la participación es más genuina y necesita un Estado. Es necesario que el Estado pueda crear las posibilidades para que la gente lo haga. Y las condiciones de vida son fundamentales para la participación. [...] Si bien alguien puede decirme que hay mucha gente en los territorios más vulnerables que se acerca a participar, ahora, con condiciones de vida más digna, es diferente"

Vemos, así, que no parece suficiente con una participación por fuera del Estado para poder concretar un proceso de cambio social como el que él y otros activistas aspiran a concretar, al mismo tiempo que el Estado es puesto como una suerte de garante en el impulso o la garantía de las condiciones para poder participar.

Otro modo de aproximarse a las relaciones entre militancia y gestión entre los socialistas tiene que ver con identificar la confluencia entre los roles partidarios y los roles en la gestión de gobierno local. Este es el caso de Martín, anteriormente mencionado, como el de Julieta (25 años, oriunda de un pueblo pequeño del sur de Santa Fe, militante en una de las seccionale ${ }^{26}$ de la ciudad, 
divide electoralmente de acuerdo con las seccionales policiales por lo que la distribución de los locales partidarios se organiza de acuerdo con estas divisiones, siendo el término "seccional", el utilizado comúnmente en la jerga de la militancia socialista para denominar a los tradicionales locales barriales. trabajadora en un Plan del Ministerio de Educación Provincial, entrevistada en Julio de 2014) quien se fue en 2007 a vivir a Rosario para estudiar, primero en un terciario y luego en la universidad, donde estudia Ciencia Política y entra en contacto con el socialismo. Si en el testimonio de Martín el trabajo del militante en la gestión se puede interpretar como una suerte de consolidación del trabajo militante propiamente dicho, en el caso de Julieta el hecho de que el Partido sea parte de la gestión provincial es puesto en un nuevo horizonte de sentido: como algo que fortalece la conformación de nuevos compromisos militantes. En este sentido, como sostiene la militante, "ahora que somos gestión, eso motiva un poco más de gente". Vemos así un nuevo sentido de la participación en relación con el Estado, que no tiene que ver solamente -como destacaba Martín-con la idea de propiciar condiciones para garantizar la participación, sino además con el hecho de que ser parte del partido a cargo de una gestión de gobierno, moviliza más y nuevas adhesiones militantes.

Por otra parte, Carolina (25 años, porteña, militante de JPRO, asesora en una de las Comunas, entrevistada en Marzo de 2013), se acerca entre 2007 y 2008 al PRO, es decir, al momento de iniciarse el gobierno del PRO en la CABA. Estudia Producción de Radio y Televisión en un terciario de gestión privada y vive como significativo el debate en torno a la denominada Ley de Medios en su espacio educativo. El primer contacto con el partido se produce por medio de las redes sociales, en su caso por Facebook y por el sitio web del partido, medios por los cuales es invitada a una primera reunión con un grupo que se estaba conformando. Por otro lado, ella comienza a participar cuando el partido ya es parte de la gestión de la CABA y es por medio de redes de relaciones tejidas en torno a su activismo como llega a tener un trabajo en la Comuna.

Entre los motivos que esgrime para explicar su acercamiento al partido, se puede observar una idea del compromiso asociada con un componente individual al mismo tiempo que con la idea de ayudar a otros. Como propone Carolina, "tengo ganas de sumar mi granito de arena, aunque no sea nada". Esto muestra algunos contrastes con la manera en que Martín, por ejemplo, relata las motivaciones de su compromiso político y el rol del Estado en relación con el mismo. Así, si en el caso de Martín el Estado constituye el modo de concretar expectativas colectivas gestadas en la construcción militante de los espacios, aquí identificamos una retórica más individualista asociada con una cierta visión pragmatista del Estado que caracteriza la visión ideológica del PRO.

Los testimonios recuperados permiten mostrar cómo para el activismo socialista la militancia es vivida como algo a consagrar desde el Estado (trabajando en áreas o programas que son vistos en relación de continuidad con una militancia gestada anteriormente y por fuera del Estado), a la vez que la gestión del Partido es interpretada como un elemento que moviliza adhesiones militantes (tanto de los militantes/trabajadores en el Estado, como de los destinatarios de aquellas acciones). En el caso del PRO, el compromiso militante aparece como un trabajo que permite ayudar a otros, que permite aportar. El ingreso a la gestión aparece destacado en una lógica que combina la dimensión altruista (ayudar a otros) con una dimensión más individual que es recuperada como más significativa que otras para narrar la llegada a la actividad partidaria. Sin embargo, en los diferentes casos vemos que el Estado aparece como un espacio privilegiado para llevar adelante transformaciones que no pueden garantizarse en la militancia por fuera del mismo (Cozachcow 2015).

Otro elemento que resulta significativo en el estudio de las carreras militantes son las expectativas generadas en torno al desarrollo de una carrera en lugares con responsabilidad partidaria, así como también en la gestión pública. Por ello, en la encuesta preguntamos a aquellos que no poseen cargos públicos si desearían tenerlos a futuro, al mismo tiempo que interrogamos a quienes 
carecen de cargos partidarios si desearían tenerlos. En el caso del PRO, el 36\% trabaja en el Estado, el 14\% sostiene que tiene un cargo público, el $17 \%$ que ocupa cargos partidarios y el $80 \%$ de los que no ocupa ningún tipo de cargo se manifiesta interesado en hacerlo, tanto para públicos como para partidarios. En el PS, el 19\% trabaja en el Estado, el 26\% ocupa cargos públicos, el $21 \%$ partidarios. Entre quienes no ocupan cargos, el $63 \%$ afirma estar interesado en tener cargos públicos y el $40 \%$ partidarios.

Al poner estos resultados en relación con los presentados más arriba acerca del trabajo en el Estado encontramos algunas relaciones significativas en varios sentidos. En primer lugar, vale destacar el peso diferencial que posee el trabajo en el Estado entre la militancia juvenil del PS (19\%) frente al PRO (36\%). Es interesante notar, además, que esta relación es inversa al momento de interrogar por los cargos públicos, que es un $12 \%$ menor en caso del socialismo. Vemos entonces que entre las personas encuestadas del PRO trabajar en el Estado no necesariamente es asociado con el hecho de ocupar un cargo público, mientras que en el PS el desarrollo laboral en cargos públicos aparece como algo mucho más amplio y abarcativo que el mero desempeño laboral en el Estado, como mencionamos anteriormente.

En segundo término, si observamos el peso que posee el desempeño en cargos partidarios, notamos que no hay una gran diferencia en ambos partidos (con el $14 \%$ en el PRO y un $21 \%$ en el PS).

En tercer término, si analizamos las expectativas de acceder a cargos, tanto partidarios como públicos, notamos que en el caso del PRO se aspira en un mismo porcentaje $(80 \%)$ a acceder a ambos tipos de espacios. Aspecto que nos permite hipotetizar que en dicho caso la vía de inserción en el Estado a cargos públicos aparece mediada por la inscripción político-partidaria. En el caso del PS notamos que las expectativas sobre los cargos públicos son mayores (en un 23\%) que sobre el acceso a cargos partidarios. Vemos así que hay una idea más amplia sobre qué significa lo público.

Finalmente, vale la pena hacer mención al diferencial de expectativas en torno al acceso a cargos partidarios, que asciende al $40 \%$ entre jóvenes de uno y de otro partido. Esto puede ser pensado en relación con dos cuestiones diferentes: por un lado, de acuerdo con el peso que posee la inscripción partidaria como vía de crecimiento y ascenso en el Estado (como se ve en el caso del PRO); por otro lado, podría dar cuenta de la proyección diferencial que presentan las juventudes dentro de cada uno de los partidos, siendo el caso del PRO aquel en el que se manifiesta, al menos desde las expectativas de sus jóvenes militantes, mayores posibilidades de acceder a cargos partidarios. Esto se condice con los resultados de investigaciones anteriores, en las que se muestra que el PRO posee un modo específico de presentación en el espacio político como partido nиevo y juvenilizado, siendo la construcción de figuras juveniles dentro del partido uno de los elementos más destacados (Núñez y Cozachcow 2016).

\section{IV.3. Espacios de socialización militante en la formación de cuadros y carreras militantes}

Uno de los elementos que permite entender la configuración de las carreras militantes en ambos partidos tiene que ver con la inserción en ciertas áreas estatales o programas que se consideran preciados dentro de los respectivos partidos. Uno de los espacios valorados en materia de gestión tiene que ver con el desempeño laboral en las áreas estatales de juventud, aspecto que permite pensar cómo se ponen en juego en el desarrollo de las carreras militantes ascendentes tanto los saberes educativos adquiridos por medio de su acceso a la 
educación formal como también con saberes adquiridos en el desarrollo laboral en la gestión.

Dentro de la gestión del PS hay una experiencia que ha cobrado mucha difusión y conocimiento público: el Gabinete Joven. Se trata de un "dispositivo institucional creado por el Gobierno de la Provincia de Santa Fe para incorporar la perspectiva joven en la construcción de las políticas públicas" (Balardini 2009, p.8). El mismo depende de la Dirección Provincial de Políticas de Juventud, que funciona en el marco del Ministerio de Innovación y Cultura. Lo interesante de este dispositivo a los fines del argumento que aquí se presenta, es doble. Por un lado, porque representa un lugar de ingreso y/o ascenso por parte de la militancia a la gestión. Por el otro, y tal como surge de la aplicación de las encuestas entre jóvenes socialistas, constituye una de las políticas públicas de juventud más conocidas y valorizadas. Cuando se les preguntó si conocían alguna política pública para jóvenes, el $60 \%$ contestó que sí y el 55\% hizo alusión a políticas implementadas por la Provincia de Santa Fe o por la Municipalidad de Rosario, siendo el Gabinete Joven una de las menciones más destacadas.

Vemos así que no solamente las relaciones entre militancia y gestión son relevantes para los propios trabajadores y funcionarios estatales, sino además un aspecto central para el resto de la militancia que ve en aquellas articulaciones algunos de los logros de su propio proyecto militante. Al mismo tiempo que una dimensión de la socialización militante se reconoce en del hecho de que los activistas estén familiarizados con las tareas de la gestión de su propio partido a nivel municipal.

En el caso del PRO, como se mencionó en §2, la participación juvenil se plasma en diferentes espacios organizativos al interior del Partido. La inscripción en una u otra de estas agrupaciones permite comprender el modo en que se trazan vinculaciones entre las experiencias militantes de los activistas y la gestión. Como vimos, los liderazgos políticos en cada una de las agrupaciones se basan en un conjunto de atributos y rasgos entre los que se destaca el rol del dirigente en el trabajo en la gestión. En algunos casos, la construcción de la narrativa partidaria busca situar a estos liderazgos adultos como símbolo para los militantes de lo que se considera como la buena gestión, definidas a partir de experiencias previas al trabajo en el Gobierno de la Ciudad (como veíamos anteriormente en el caso del Macri) como por el desempeño de los funcionarios en las gestiones macristas en la CABA. Lo interesante es tomar nota, por un lado, del modo en que a la luz de estos liderazgos se observa una confluencia entre el rol laboral y el liderazgo político en el espacio partidario. Por otro lado, y como contrapunto de la militancia en el socialismo, que las credenciales válidas y legítimas para este universo de relaciones tienen más que ver con carreras laborales propiamente dichas que con carreras militantes.

Las agrupaciones internas juveniles del PRO representan también un espacio de socialización militante en términos del aprendizaje de un saber hacer específico. Fernando (35 años, ex Presidente de la JPRO CABA, director en una empresa pública de la CABA, entrevistado en Septiembre de 2013) refiere a la militancia en el espacio juvenil como la escuelita en la que se realiza este proceso.

Entrevistadores: ¿Cómo llegaste a ser Presidente [de JPRO]?

F: Haciendo la escuelita.

Entrevistadores: ¿O sea, esa escuelita la pensaban como para ustedes o para futuros ingresantes?

F: Para futuros dirigentes. Nosotros siempre, yo al menos, mi visión es la escuelita para tener hoy dirigentes. O sea, empezás en la juventud como soldado 
raso si querés, [...] Después sos dirigente de la juventud, en algún cargo de alguna secretaría y se va haciendo como la escuela, van ganando experiencia. Era como un proceso de formación política, había una secretaría de formación política había una estructura organizada que te permitía tener este proceso de aprendizaje. Y uno arrancaba como militante de base entre comillas, y después ibas ganando lugares dentro de la propia organización de juventud.

La gestión del PRO en la CABA también tiene una Dirección General de Políticas de Juventud que presenta una conceptualización diferente a la del socialismo. Aunque por motivos de espacio no será abordada en este trabajo, nos interesa destacar que por esta Dirección han pasado todos los presidentes de la JPRO CABA entre 2007 y 2013, ya sea como Directores o como empleados de la misma. Asimismo, el paso por la Dirección aparece como parte de un recorrido ascendente en los itinerarios laborales y militantes de los activistas.

Ahora bien, la relación recursiva entre militancia y gestión no parece ser exclusiva del universo del PRO. En efecto, y a título ilustrativo, Guillermo (29 años, Rosarino, dirigente juvenil socialista, entrevistado en noviembre de 2012) asocia el crecimiento del espacio juvenil en el socialismo con el "crecimiento de la figura de nuestro compañero Binner", más precisamente con la visibilización de quien fue Gobernador de Santa Fe como potencial presidenciable y el modo en que esto redundó en un crecimiento de la participación juvenil. De modo que podemos ver cómo se construyen diferentes relaciones entre la gestión y la militancia que no se agotan en la propia experiencia de los activistas sino que, además, el desempeño como responsable del Poder Ejecutivo a nivel Provincial así como el potencial desempeño a nivel Nacional, aparecen como elementos que configuran y movilizan adhesiones militantes juveniles. En consonancia con el testimonio de Julieta, ser gestión también para el PS representa un modo de construir nuevas adhesiones militantes.

Por otra parte, a partir de las Primarias Abiertas Simultáneas y Obligatorias (PASO) del año 2015 se observa en el en el PS santafesino un importante recambio generacional que se manifiesta con la llegada a lugares expectantes de dirigentes juveniles en las listas del Frente Progresista Cívico y Social, tanto en la Provincia como en Rosario, siendo que algunos de ellos fueron electos como Diputados Provinciales o Concejales en la ciudad de Rosario, o designados en cargos con rango de Directores o Secretarios tanto a nivel provincial como municipal.

Como se desprende de las ideas presentadas, las relaciones militancia y gestión abren un amplio espectro de sentidos y configuraciones en ambos partidos, los cuales no admiten lecturas simplistas y parciales. Los diferentes temas tratados en este apartado evidencian que para ser considerado un legítimo militante no parece suficiente con desempeñarse exitosamente en el plano laboral en la gestión pero tampoco tener un rol en el ámbito partidario y permanecer por fuera -o no ser competente- en el campo burocrático-administrativo. En este sentido, observamos la importancia que reviste la validación de capitales y saberes específicos vinculados con el universo militante para el desempeño como trabajadores y responsables de áreas y programas estatales, así como también la centralidad que cobra la legitimación militante de saberes y capitales propios del mundo laboral o empresarial del que algunos de los activistas y dirigentes provienen, sobre todo en el caso del PRO.

Estas complejas determinaciones son ilustrativas de cómo y por qué la militancia partidaria juvenil encuentra en el trabajo en el Estado un objeto aspiracional. Además, permiten explicar por qué el desempeño laboral en determinadas áreas, programas o en relación con ciertos jefes (laborales y políticos) es vivido como parte de una formación militante, en relación con la cual la imagen de la escuelita resulta realmente productiva. Finalmente, estas 
${ }^{27}$ Sobre esta cuestión es importante tener en cuenta las diferencias que presenta el PRO en su proyección al año 2015. Esto ha generado transformaciones en los espacios juveniles, principalmente los de la CABA, por las que muchos jóvenes pasan del Gobierno de la Ciudad al Nacional, propiciando aún más el proceso de ascenso vertiginoso ya señalado. Gobierno Nacional desde el

relaciones permiten comprender cómo se configura un repertorio de acciones militantes en el que se incluye trabajar en el Estado y en el cual los jóvenes también deben socializarse.

Por último, las relaciones estudiadas permiten advertir las fronteras porosas del quehacer militante entre los partidos que son, a la vez, gestión. En estos casos, la participación y la militancia se repiensa en nuevos marcos de sentido (en el socialismo) o se configura con marcas específicas de origen (en el PRO), a la vez que los proyectos de gestión son modelados de acuerdo con las particularidades de los modos de participación, compromiso y construcción política de cada uno de los partidos. En otras palabras, la militancia modifica y es modificada por la gestión, al mismo tiempo que la gestión modifica y es modificada según los respectivos modelos de militancia.

Por todo lo dicho, las relaciones entre militancia y cargos en el Estado, así como las interpretaciones y sentidos construidos acerca de estas relaciones, nos muestran una complejidad que se aleja de las miradas simplistas que tienden a asociar el activismo con la búsqueda por obtener retribuciones materiales. La posibilidad de tener un cargo en la gestión a nivel subnacional aparece, en ambos partidos aunque con matices en cada caso, anudada a una experiencia de militancia ${ }^{27}$. La gestión, aunque también con matices, introduce cambios en esa militancia puesto que la legitima y rejerarquiza, al mismo tiempo que acelera, el desarrollo de carreras (laborales, profesionales y militantes) exitosas. En este sentido se observa que la construcción de los espacios militantes juveniles se encuentran más condicionados por la gestión en el PRO que en el PS, debido al peso significativo que tiene la militancia estudiantil universitaria en este último. Asimismo, en relación con el tipo de saber experto que es valorado, se observa que en el PRO este no está solamente asociado a la gestión pública, como en el caso del PS, sino también con el sector privado. Ahora bien, no se trata de ingresar a trabajar en el Estado, sin más, sino que se observa una reconversión específica de saberes de un espacio (de militancia) a otro (laboral) y viceversa. En otros términos, el tratamiento de la cuestión juvenil (con la que se vinculan como parte de su militancia en espacios diferenciados del partido como también con el desarrollo de acciones estatales en áreas y políticas específicas), pasa a ser valorado como un saber experto y especializado que estos militantes detentan y que los posiciona en un lugar de legitimidad específico, al que no podrían aspirar igualmente otros militantes partidarios. Así es como entre la militancia y la gestión, los y las jóvenes militantes terminan de construir un modo de ser parte del partido que es propio y que se diferencia del de los adultos. Detentar saberes para la militancia/gestión con juventudes representa un capital del que estos no son, ni pueden aspirar a ser, portadores.

\section{Conclusiones}

Para terminar este trabajo proponemos repasar algunas de las cuestiones abordadas a lo largo del artículo con el fin de sistematizar algunas características que posee la militancia juvenil vinculada con la revitalización del activismo político partidario en Argentina, por un lado, y con la condición de ser militantes de partidos en gestión de gobierno, por otro.

En primer lugar, el uso de una aproximación descriptiva del activismo permite mostrar quiénes son los y las jóvenes militantes en los espacios partidarios estudiados. Encontramos que en ambos casos se trata de jóvenes que en su gran mayoría estudian y trabajan y en los que el medio universitario cobra particular importancia, sea como modo de reclutamiento o de adquisición de saberes valorados en una militancia que está asociada a la gestión. Por otra parte, se trata de jóvenes que militan en partidos y carecen de experiencias previas en otros espacios de militancia, es decir que se forman como militantes 
${ }^{28}$ Cabría pensar en este sentido cuál es el impacto que tiene la proyección a la gestión nacional del PRO, por medio de la alianza CAMBIEMOS, en la conformación de las carreras militantes. Sería interesante en este sentido, realizar investigaciones a futuro que aborden el modo en que se reconfiguran de las trayectorias militantes de los jóvenes. casi íntegramente en el activismo partidario. Esto no solamente es importante para pensar el tipo de socialización político-partidaria que poseen, sino además el hecho de que esos partidos son parte de una gestión de gobierno durante el inicio y desarrollo de su participación. Ahora bien, esto está lejos de mostrar carreras militantes homogéneas. En el PS se observa un modelo de militancia tiene en el ámbito universitario el punto de origen en el desarrollo de una carrera militante que implica, luego, el paso al partido y, eventualmente, a la gestión. En el caso del PRO, los recorridos y los ascensos militantes de los jóvenes se producen de modo más rápido, en parte debido a la corta existencia del mismo en tanto fuerza política ${ }^{28}$, pero además por el modo específico de autopostularse como un partido nuevo y juvenilizado que, como vimos, destaca especialmente a sus figuras jóvenes.

En segundo término, el enfoque teórico y metodológico escogido resulta fundamental a la hora de evaluar los aportes del presente trabajo. Desde la mirada de la Ciencia Política, tal como fue caracterizada desde el trabajo de Franz (2016), las diferencias entre un partido como el Socialista y el PRO serían enormes. Ahora bien, visto desde las lógicas del compromiso militante en experiencias que (aunque dispares ideológicamente) comparten el hecho de ser partidos en/de la gestión, es factible poner en relación e identificar un conjunto de aspectos comunes, como también de diferencias, que vuelven el análisis menos estático, más rico y complejo. Por ello, más allá de las diferencias superestructurales en cuanto a ideología, historia del partido y de los espacios de juventud, el trabajo permite identificar aspectos comunes en la construcción de los modelos de compromiso juvenil que los vuelven comparables.

En ambos casos, la cuestión juvenil pasa a cobrar un nuevo interés y se integra como tema de la agenda militante. Además, se observa con claridad que la dinámica partidaria en torno a la disputa electoral incide en la construcción de compromisos militantes. Como vimos, una buena cantidad de los nuevos ingresos de activistas jóvenes se producen durante las campañas. Por otra parte, la revitalización de la militancia juvenil en ambos partidos se produce de modo coincidente con el desarrollo de gestiones subnacionales, siendo este un aspecto fuertemente estructurador de esas (nuevas) militancias, especialmente porque -como dijimos- los y las jóvenes se forman íntegramente en esos partidos. Si retomamos el testimonio de Julieta, una de las entrevistadas del PS, notamos que ser gestión genera una mayor motivación entre la militancia juvenil de su partido. Esto se corrobora, además, en las encuestas, en las que vemos que el ingreso al Estado se configura como expectativa asociada a esa militancia (ya sea por medio de la participación partidaria, o no). Reconocemos, así, propiedades en torno a esta militancia que no se reconocen en otros espacios militantes ni tampoco en otros momentos de la historia, por ejemplo aquellos en los cuales la movilización política juvenil en Argentina se configuró desde el cuestionamiento a las instituciones estatales como ocurrió en la década de los noventa (Bonvilani et al., 2010).

En tercer lugar, y de modo complementario con el punto anterior, las carreras militantes estudiadas reconocen interesantes puntos de contacto con las carreras laborales dentro del Estado. Más concretamente, en el artículo buscamos mostrar cómo se construyen en cada caso las articulaciones y reconversiones entre las carreras y los capitales militantes y laborales. El análisis nos alerta sobre las lecturas reduccionistas que tienden a explicar la militancia en los partidos que son gestión como resultado de un interés o cálculo asociado con la posibilidad de tener cargos en la gestión estatal. En este sentido, como vimos, son muchos y heterogéneos los sentidos, las razones y las maneras en que se conectan militancia y trabajo en el Estado, siendo todos estos elementos plausibles de ser pensados como incentivos selectivos en el sentido que les confiere Gaxie (2015). 
En ambos partidos se construyen articulaciones y reconversiones entre las carreras militantes y laborales. Resulta interesante, así, que la militancia -aunque con diferentes intensidades- construye expectativas en torno al desarrollo de carreras laborales y profesionales por parte de los y las jóvenes. Asimismo, es interesante observar que la militancia en espacios de juventud se convierte en una suerte de expertise que los vuelve especialmente valorados y competentes en la inserción de áreas específicas del Estado a nivel provincial, como son las áreas de juventud o las políticas de juventudes. Vemos así cómo el capital militante es reconvertido en capital burocrático-administrativo. Estos elementos comunes presentan, de todos modos, especificidades y diferencias que se desprenden, por ejemplo, del hecho de que el PRO surge como partido que accede rápidamente a la gestión, mientras que el Partido Socialista nace antes y por fuera de la gestión, a la que llega más tardíamente a nivel provincial. Es así como se reconocen diferencias en los tiempos y en los modos de dar el salto del espacio militante al espacio estatal.

Para terminar, los partidos elegidos resultan interesantes para analizar las relaciones entre la militancia, la movilización política y juventudes en relación con casos subnacionales que han sido relativamente poco estudiados, al menos en términos comparativos con la exploración de los vínculos entre la militancia juvenil y las gestiones de gobierno a nivel nacional durante el kirchnerismo. Esto resulta interesante porque permite pensar las mencionadas vinculaciones en otra escala pero además, y fundamentalmente, porque permite mostrar cómo se movilizan adhesiones militantes en gestiones de gobierno que no se inscriben dentro de la tradición nacional y popular. En algunos análisis se ha señalado que esta tradición aparece como aquella que se muestra con mayor potencial para desplegar adhesiones militantes, sin embargo los casos que aquí se abordan muestran modelos alternativos y heterogéneos en términos político-ideológicos que también han propiciado fuertemente la construcción de (nuevos) compromisos militantes juveniles. En este sentido, el trabajo nos invita a pensar en la revitalización de la participación juvenil como elemento transversal a diversos partidos incluso con posicionamientos político-ideológicos marcadamente diferentes.

Melina Vázquez (mvazquez@ sociales.uba.ar) es Doctora en Investigación en Ciencias Sociales por la Universidad de Buenos Aires (Argentina), Posdoctora en Investigación en Ciencias Sociales, Infancia y Juventud (CLACSO), Investigadora Adjunta del CONICET y Profesora Adjunta a cargo de la matéria Sociología de la Infancia, Adolescencia y Juventud de la Universidad de Buenos Aires. Vinculación Institucional: Equipo de Estudios de Políticas y Juventudes, Instituto de Investigaciones Gino Germani (IIGG-UBA) y Consejo Nacional de Investigaciones Científicas y Técnicas (CONICET), Ciudad Autónoma de Buenos Aires, Argentina.

Alejandro Cozachcow (alecoza@ gmail.com) es Doctorando en Ciencias Sociales por la Universidad de Buenos Aires (Argentina), y Docente de Sociología de la Infancia, Adolescencia y Juventud de la Universidad de Buenos Aires. Vinculación Institucional: Equipo de Estudios de Políticas y Juventudes, Instituto de Investigaciones Gino Germani (IIGG-UBA), Ciudad Autónoma de Buenos Aires, Argentina.

\section{Referências}

Acosta, G., 2011. Jóvenes en la política partidaria: Una aproximación a las organizaciones de juventud vinculadas a los partidos políticos en Colombia. Anagramas, 9(19), pp.51-68. DOI: 10.22395/angr.v10n19a3

Aguilera, R.O., 2011. Acontecimiento y acción colectiva juvenil. El antes, durante y después de la rebelión de los estudiantes chilenos en el 2006. Propuesta Educativa1, 35, pp.11-26.

Agrikoliansky, E., 2001. Carrières militantes et vocation a la morale: les militants de La Ligue Des Droits de l'homme dans les années 1980. Revue Française de Science Politique, 51(1), pp. 27-46. DOI: 10.3406/rfsp.2001.403606

Balardini, S., 2009. El Gabinete Joven. Una política innovadora del Gobierno de Santa Fe. Buenos Aires: Fundación Friedrich Ebert.

Barberá, O.; Barrio, A. \& Rodriguez, J., eds., 2002. Els militants de les prganitzacions polítiques juvenils a Catalunya. Barcelona: Diputació de Barcelona. 
Bargel, L. \& Petitfils, A., 2009. 'Militants et populaires!' Une organisation de jeunesse sarkosyste en campagne. L'activation pèriodique d'une offre organisationnelle de militantisme et ses appropriations pratiques et symboliques. Revue Française de Science Politique, 59(1), pp.51-75. DOI: 10.3917/rfsp.591.0051

Beltrán, M. \& Falconi, O., 2011. La toma de escuelas secundarias en la ciudad de Córdoba: condiciones de escolarización, participación política estudiantil y ampliación del diálogo social. Propuesta Educativa, 35(1), pp.27-40.

Binderm, A. \& Wood, K., 2013. Becoming Right: How Campuses Shape Young Conservatives. Princeton: Princeton University Press.

Bonvilani, A.; Palermo, A.; Vázquez, M. \& Vommaro, P., 2010. Del Cordobazo al kirchnerismo. Una lectura crítica acerca de los períodos, temáticas y perspectivas en los estudios sobre juventudes y participación política en la Argentina. In S.V. Alvarado \& P.A. Vommaro, eds. Jóvenes, cultura y política en América Latina: algunos trayectos de sus relaciones, experiencias y lecturas (1960-2000). Rosario: Homo Sapiens.

Brenner, A., 2012 Brasil: compromiso de los jóvenes en los partidos políticos. Diálogo Político, 29(3), pp.147-177.

Castro Rocha, D., 2009 Les jeunes du Parti des Travailleurs à l'épreuve de la crise du militantisme. Modes d'entrée et carrières militantes des jeunes petistas de Brasilia. Agora: Débats/jeunesses, 2(52), pp.89-104. DOI: 10.3917/agora.052.0089

Cipagauta, H.J.C.; Borelli, S.; Vázquez. M. \& Lara, R.U., 2015. Juventudes latinoamericanas: practicas socioculturales, políticas y políticas públicas. Buenos Aires: CLACSO.

Cozachcow, A., 2015 La militancia juvenil en partidos políticos en la Argentina post 2003. Motivos de participación, itinerarios militantes y vínculos generacionales en el Partido Socialista y el PRO (2012-2014). Tésis de Maestría. Universidad Nacional de Genral Sarmiento/Instituto de Desarrollo Económico y Social.

Dechezelles, S., 2008. Des partis et des jeunes. Les droites juvéniles dans 1'Italie de Berlusconi. Historie @ Politique, 4(1), p.14. DOI: $10.3917 / \mathrm{hp} .004 .0014$

Enrique, I., 2010. Movilización estudiantil en la Ciudad de Buenos Aires: aportes para el análisis. Boletín de Antropología y Educación, 1, pp.1-6.

Espinoza, V. \& Madrid, S., 2010. Trayectoria y Eficacia Política de los militantes en juventudes políticas. Santiago: Universidad de Santiago de Chile.

Fillieule, O., 2015. Propuestas para un análisis procesual del compromiso individual. En Intersticios. Revista Sociológica de Pensamiento Crítico, 9(2), pp.197-212.

Franz, W.F.N., 2016. Aderentes e militantes: a participação político-partidária na era do Partido Cartel. Revista de Sociologia e Política, 24(60), pp.91-113. DOI: 10.1590/1678-987316246004

Gaxie, D., 2015. Retribuciones de la militancia y paradojas de la acción colectiva. Intersticios, 9(2), pp.131-153.

Grandinetti, J., 2015. "Mirar para adelante". Tres dimensiones de la juventud en la militancia de Jóvenes PRO. In G. Vommaro \& S. Morresi, eds. Hagamos equipo: Pro y la construcción de la nueva derecha en Argentina. Buenos Aires: Universidad Nacional de General Sarmiento.

Hooghe M. \& Stolle D., 2005 Youth Organizations within Political Parties: Political Recruitment and the Transformation of Party Systems. In J. Forbrig, ed. Revisiting Youth Political Participation. Challenges for Research and Democratic Practice in Europe. Estrasburgo: Council of Europe.

Lafont, V., 2001. Les jeunes militants du Front national: trois modèles d'engagement et de cheminement". Revue Française de Science Politique, 51(1), pp.175-198. DOI: 10.3406/rfsp.2001.403612

Lizbona, A., 2012. La militancia de las y los jóvenes en Uruguay, ¿Su carrera política? Revista de Divulgación Científica, 2 , pp.7-22.

Mauro, S., 2016. El imperativo estratárquico y los actores extrabipartidistas. Los casos del PRO y del PS (2003-2013). In S. Mauro; V. Ortiz de Rozas \& M. Paratz, eds. La política subnacional en Argentina. Enfoques y problemas. Buenos Aires: UBA.

Mauro, S.; Ortiz de Rozas, V. \& Paratz, M., eds., 2016 La política subnacional en Argentina. Enfoques y problemas. Buenos Aires: UBA.

Molinari, V. 2010. La participación política de los jóvenes dentro de las orgánicas partidarias. In II Reunión Nacional de Investigadoras/es en Juventudes de Argentina. Salta.

Mustapic, A.M., 2002. Argentina: La crisis de representación y los partidos políticos. America Latina Hoy, 32, pp.163-183.

Mutuverría, M., 2016. Militantes y Estado. Prácticas de Oficio, 2(18), pp.1-13.

Núñez, P., 2013. La política en la escuela: jóvenes, justicia y derechos en el espacio escolar. Buenos Aires: La Crujía.

Núñez, P. \& Cozachcow, A., 2016. Llueve pero hay “alegría” en la Ciudad: Retrato del acto de lanzamiento de la campaña electoral 2013 de la juventud del PRO de la CABA. Revista Postdata, 21(1), pp.269-302.

Offerlé, M., 1998. Sociologie des groupes d'intérêt. Paris: Montchrestien. ,2011. Perímetros de lo político: contribuciones a una socio-historia de la política. Buenos Aires: Antropofagia.

Pudal, B., 2011. Los enfoques teóricos y metodológicos de la militancia. Revista de Sociología, 25, pp.17-35. DOI: 10.5354/0716-632x.2011.27495

Perelmiter, L., 2010. Militar el Estado. La incorporación de movimientos sociales de desocupados en la gestión de políticas sociales. Argentina (2003-2008). In A. Massetti; V. Ernesto \& M. Gómez, eds. Movilizaciones, protestas e identidades políticas en la Argentina del Bicentenario. Buenos Aires: Nueva Trilce.

, 2011. Saber asistir: técnica, política y sentimientos en la asistencia estatal. Argentina (2003-2008). In S. Morresi \& G. Vommaro, G., eds. Saber lo que se hace. Expertos y política en la Argentina. Buenos Aires: Prometeo.

Pudal, B., 2011. Los enfoques teóricos y metodológicos de la militancia. Revista de Sociología, 25, pp.17-35. 
Reyna, M. \& Rigay-Pflaum, M., eds. 2009. Santa Fe, una nueva gestión en la política. Buenos Aires: Fundación Friedrich Ebert.

Sawicki, F., 2011. Para una sociología de los entornos y las redes partidistas. Revista de Sociología, 25, pp. 37-53. DOI: $10.5354 / 0716-632 x .2011 .27497$

Valenzuela Arce, J.M., ed., 2015. El sistema es antinosotros. Culturas, movimientos y resistencias juveniles. México: UNAM.

Vázquez, M., 2014. «Militar la gestión»: una aproximación a las relaciones entre activismo y trabajo en el Estado a partir de las gestiones de gobierno de Cristina Fernández de Kirchner en Argentina. Apuntes, 41(74), pp.71-102. DOI: 10.21678/apuntes.74.703

2015. Del que se vayan todos a militar por, para y desde el Estado. Desplazamientos y reconfiguraciones del activismo y las causas militantes luego de la crisis de 2001 en Argentina. In J.M. Valenzuela Arce, ed. El sistema es antinosotros. Culturas, movimientos y resistencias juveniles. México: UNAM.

Vázquez, M. \& Cozachow, A., 2015. Entre la militancia y la gestión: sentidos del activismo y formas del compromiso militante en espacios juveniles político partidarios. Una aproximación desde la Juventud Socialista y la Juventud del PRO. In $X V$ Jornadas Interescuelas/Departamentos de Historia. Chubut.

Vázquez, M.; Rocca Rivarola, D. \& Cozachcow, A., 2016. Fotografías de las juventudes militantes en Argentina. Un análisis de los compromisos políticos juveniles en el Movimiento Evita, el Partido Socialista y el PRO entre 2013 y 2015 . In M. Vázquez; P. Vommaro; P. Núñez \& R. Blanco, eds. Militancias juveniles en la argentina democrática. Trayectorias, espacios y figuras de activismo. Buenos Aires: Ediciones Imago Mundi.

Vázquez M. \& Vommaro, P., 2012. La fuerza de los jóvenes: aproximaciones a la militancia kirchnerista desde La Cámpora. In G. Pérez \& A. Natalucci, eds. Vamos las bandas. Organizaciones y militancia kirchnerista. Buenos Aires: Nueva Nueva Trilce.

Victal, M.I., 2017. Jovens de partido: práticas políticas no partido dos trabalhadores de São Paulo (2012-2013). Tesis doctoral en Ciencias Sociales. São Paulo: Pontifícia Universidade Católica.

Vommaro, G., 2015. Juventudes y políticas en la Argentina y en América Latina. Tendencias, conflictos y desafíos. Buenos Aires: Grupo Editor Universitario.

Vommaro, G. \& Morresi S., eds., 2015. Hagamos equipo: Pro y la construcción de la nueva derecha en Argentina. Buenos Aires: Universidad Nacional de General Sarmiento.

Vommaro, G.; Morresi, S. \& Bellotti, A., 2015. Mundo Pro. Anatomía de un partido fabricado para ganar. Buenos Aires: Planeta.

Young, L. \& Cross, W., 2008. Factors Influencing the Decision of the Young Politically Engaged to Join a Political Party. An Investigation of the Canadian Case. Party Politics, 14(3), pp.345-369. DOI: 10.1177/1354068807088126 


\title{
Youth Activism in Subnational Government Parties in Argentina (2007-2015)
}

\begin{abstract}
The paper aims to analyze the determinations of the recent period of youth political participation in Argentina, which highlights the importance of the political parties. After a deep crisis of political representation -that led youth activism to the impugnation of politics in connection to the State and party representation-, political parties recreated youth activism spaces and became receptors, at the same time, for new activists joining politics. In this process, the ruling parties at a national and subnational level need to be investigated in order to understand the mutations on the youth political participation. This paper seeks to analyze the features, properties and characteristics that shaped a new figure of activism among youth in relation to these experiences. More specifically, it focuses in the way in which they get involved in politics, the meanings given to political commitment, and the connection between their simultaneous conditions of young activists and workers of the public administration, regarding two parties: the Partido Socialista activists, which is the governing party in Santa Fe Province, and Propuesta Republicana activists, the ruling party in the city of Buenos Aires. To do this, we will draw upon the French sociology concept of activism, which will allow us to analyze the profile of the young activists in both parties, the ways in which they get involved into them and the connection between their work and their militant careers. This approach also lets us recognize and analyze common elements in youth party participation beyond the aspects that make these activists so different, such as their history, their ideological positions and the ways in which they are internally organized. This article is part of a wider investigation on youth participation in political parties in Argentina, carried out by the Equipo de Estudios de Políticas y Juventudes (IIGG-UBA). In this particular case, we recovered in-depth interviews to youth leaders and activists with different levels of responsibility inside each party, surveys applied with youth people from both parties, and participant observations on meetings defined by both parties as juvenile.
\end{abstract}

Keywords: youth; Argentinian politics; militancy; political parties; political participation.

This is an Open Access article distributed under the terms of the Creative Commons Attribution Non-Commercial License which permits unrestricted non-commercial use, distribution, and reproduction in any medium provided the original work is properly cited. 
Apéndice I - Lista de siglas

CABA - Ciudad Autónoma de Buenos Aires

EPOJU - Equipo de Estudios de Políticas y Juventudes

IIGG - Instituto de Investigaciones Gino Germani

JPRO - Jóvenes PRO

JS - Juventud Socialista

MNR - Movimiento Nacional Reformista

PRO - Propuesta Republicana

PS - Partido Socialista

PSD - Partido Socialista Democrático

PSP - Partido Socialista Popular

UBA - Universidad de Buenos Aires

UCA - Universidad Católica Argentina

UNL - Universidad Nacional del Litorial

UNR - Universidad Nacional de Rosario

USAL - Universidad del Salvador 